\title{
It Takes Time to Prime: Semantic Priming in the Ocular Lexical Decision Task
}

\author{
Renske S. Hoedemaker and Peter C. Gordon \\ University of North Carolina at Chapel Hill
}

\begin{abstract}
Two eye-tracking experiments were conducted in which the manual response mode typically used in lexical decision tasks (LDTs) was replaced with an eye-movement response through a sequence of 3 words. This ocular LDT combines the explicit control of task goals found in LDTs with the highly practiced ocular response used in reading text. In Experiment 1, forward saccades indicated an affirmative lexical decision (LD) on each word in the triplet. In Experiment 2, LD responses were delayed until all 3 letter strings had been read. The goal of the study was to evaluate the contribution of task goals and response mode to semantic priming. Semantic priming is very robust in tasks that involve recognition of words in isolation, such as LDT, but limited during text reading, as measured using eye movements. Gaze durations in both experiments showed robust semantic priming even though ocular response times were much shorter than manual LDs for the same words in the English Lexicon Project. Ex-Gaussian distribution fits revealed that the priming effect was concentrated in estimates of tau $(\tau)$, meaning that priming was most pronounced in the slow tail of the distribution. This pattern shows differential use of the prime information, which may be more heavily recruited in cases in which the LD is difficult, as indicated by longer response times. Compared with the manual LD responses, ocular LDs provide a more sensitive measure of this task-related influence on word recognition as measured by the LDT.
\end{abstract}

Keywords: semantic priming, goal-driven processing, response-time distributions, lexical decision, eye tracking during word reading

Isolated word recognition tasks are an extremely popular tool for studying language at all levels of processing. In particular, the lexical decision task (LDT; Meyer \& Schvaneveldt, 1971; Rubenstein, Garfi, \& Millikan, 1970) has become a staple of psycholinguistic research. In addition to its steady growth in popularity as evidence in psychological research, applications now include several megastudies, such as the English Lexicon Project (ELP; Balota et al., 2007) and the Groot Nationaal Onderzoek Taal, organized across Flanders and The Netherlands (Brysbaert, Keuleers, Mandera, \& Stevens, 2013). Studies of the recognition of words presented in isolation and during text reading have yielded highly consistent evidence about many facets of word recognition (Schilling, Rayner, \& Chumbley, 1998), suggesting there is a substantial amount of overlap between the processes required for successful performance on isolated word recognition tasks and the reading of text for comprehension. However, differences in the specific demands made by each task require more detailed understanding

This article was published Online First September 1, 2014

Renske S. Hoedemaker and Peter C. Gordon, Department of Psychology, University of North Carolina at Chapel Hill.

This research was supported by R01 HD060440-06A2 to PCG from the National Institute of Child Health and Human Development. We thank Kristine Chen, Rachael Jones, Matt Lowder, Mariah Moore, and members of the Language Cognition Brain group at University of North Carolina Chapel Hill for help with this project.

Correspondence concerning this article should be addressed to Peter C. Gordon, Department of Psychology, CB\#3270, University of North Carolina at Chapel Hill, Chapel Hill, NC 27599-3270. E-mail: pcg@unc.edu before evidence from isolated word recognition studies can be used directly to improve our understanding of word recognition during text reading.

Like other tasks for studying the recognition of isolated words, LDTs impose a specific processing goal while also providing an overt measure (response accuracy) of success in achieving that goal. This direct link between the response and the task goal is an important part of the justification for treating response time as a measure of the difficulty of word recognition in an LDT. In contrast, the difficulty of word recognition during sentence reading is typically measured by gaze duration, the time that a word is fixated during first-pass reading under circumstances in which participants are asked to "read naturally," and the explicit task goal, if any, focuses on the meaning of the sentence or larger text (Inhoff, 1984; Morris, 1994; Rayner, 1998). Consequently, the response of advancing the eyes from one word to the next is based on criteria that cannot be assessed directly, and it is well established that eye movements during reading are shaped by many factors, ranging from the limits of visual acuity and temporal constraints on generating saccades to the dependence of comprehension on the integration of meanings from different parts of a text (Engbert, Nuthmann, Richter, \& Kliegl, 2005; Gordon, Plummer, \& Choi, 2013; Rayner \& Pollatsek, 1989; Reichle, Pollatsek, \& Rayner, 2006). As a result, linking eye movements to specific levels of word recognition is model dependent, with models of oculomotor control during reading being a focus of intense interest and debate (Engbert et al., 2005; Gordon et al., 2013; Rayner \& Pollatsek, 1989; Reichle, Rayner, \& Pollatsek, 2003; Reilly \& Radach, 2006). 
In addition to their important differences with respect to response goals and criteria, lexical decisions (LDs) and gaze durations for words during reading typically involve measurement of responses made by very different motor systems, with LD times obtained by recording manual button presses (or occasionally vocal responses), and gaze durations obtained by recording eye movements. For skilled readers, the response of moving the eyes from one word to the next during reading is highly practiced. In contrast, isolated word recognition tasks require participants to use a far less practiced response mode, together with response mappings that have little connection to natural reading. Response times in manual LD tasks are roughly double the gaze durations observed for the same words during reading (e.g., Balota et al., 2007; Balota \& Chumbley, 1984; Inhoff, 1984; McNamara, 2005; Morris, 1994; Rayner, 1998). Given that response times to words in LDTs are strongly influenced by task factors such as type of nonword (Lupker \& Pexman, 2010; Stone \& Van Orden, 1993), it is likely that processing demands of making an LD account for some portion of the difference between manual LD response times and gaze durations, but the possible contribution of the type of motor response to this difference has not been assessed.

The phenomenon of semantic priming - the facilitation in processing a word when it is preceded by a semantically (or associatively) related word-shows the importance of understanding how experimental observations are influenced by task demands and response mode. Semantic priming is robust in tasks involving the recognition of words in isolation (LDTs and speeded pronunciation); although there are well-documented boundary conditions on its occurrence (Balota \& Lorch, 1986; Forster, 1981; Keefe \& Neely, 1990), within those boundaries, the effect is very robust (de Groot, 1984; Hutchison, Balota, Cortese \& Watson, 2008; McNamara, 2005; McNamara \& Altarriba, 1988; Neely, 1977; Shelton \& Martin, 1992). Semantic priming effects have been taken to reflect both fundamental mechanisms of retrieval from memory (Masson, 1995; McNamara, 1992; Plaut \& Booth, 2000; Ratcliff \& McKoon, 1988) and true relations of meaning within the organization of semantic knowledge (McNamara, 2005). Accordingly, semantic priming is a foundational component of many influential models of word recognition, memory retrieval, and general cognitive functioning, such as spreading activation models (Anderson, 1983; Collins \& Loftus, 1975) and distributed network models (McRae, de Sa, \& Seidenberg, 1997; Rumelhart \& McClelland, 1986).

Given the prominence of semantic priming research, it is surprising that reading studies using eye tracking have provided only a few demonstrations of semantic priming on gaze durations for words as a function of whether a preceding word in the sentence is semantically related. Further, this effect is heavily constrained by the syntactic structure of the sentence (Carroll \& Slowiaczek, 1986; Morris \& Folk, 1998), and appears to be easily overridden by message-level factors such as congruity, predictability, and presence of discourse context (Camblin, Gordon, \& Swaab, 2007; Morris, 1994; Tabossi, 1982; Traxler, Foss, Seely, Kaup, \& Morris, 2000). Morris (1994) observed within-sentence priming effects only in cases in which the target word was congruent in the sentence context, even though the lexical context was kept constant. For example, priming on the target word "mustache" was shown for "The gardener talked as the barber trimmed the mustache," but not for "The gardener talked to the barber and trimmed the mustache." A strong influence of global discourse coherence over local sentence-based relationships was demonstrated by Camblin et al. (2007). Eye-tracking measures showed effects of withinsentence lexical association, but only when sentences appeared in isolation or in larger but incoherent discourse contexts (see also Boudewyn, Gordon, Long, Polse, \& Swaab, 2012, for eventrelated potential [ERP] analyses of congruence and priming during spoken language comprehension). When the same sentences were presented in a coherent larger discourse context, priming effects between semantically related words were strikingly absent.

Semantic priming during text reading has also been studied using two gaze-contingent display techniques, the boundary paradigm (Rayner, 1975), and the fast-priming paradigm (S. C. Sereno \& Rayner, 1992). The boundary paradigm assesses whether viewing a related word in the parafovea primes foveal processing of a target word. This is done by having a related or unrelated prime word appear in the location of the target word, with the target word appearing only after the eyes cross an invisible boundary at the left edge of the prime-target location. The preponderance of evidence for English is that reading times for the target word are not affected by semantic relatedness of the parafoveal prime (Altarriba, Kambe, Pollatsek, \& Rayner, 2001; Rayner, Balota, \& Pollatsek, 1986; Rayner \& Schotter, 2014; Rayner, Schotter, \& Drieghe, 2014, also see Schotter, Angele, \& Rayner, 2012, for a review of parafoveal processing effects), with one study demonstrating a significant parafoveal preview benefit for synonyms, but not other types of semantically related preview words (Schotter, 2013). In the fast-priming paradigm, the prime word is presented foveally for 20 to $60 \mathrm{~ms}$ before being replaced by the target word. Semantic priming has been found in this paradigm, but the effects are surprisingly sensitive to the exact duration of the prime, with one study finding significant fast priming with 30 -ms primes but not with primes that were $21,39,45$, or $60 \mathrm{~ms}$ (S. C. Sereno \& Rayner, 1992), and a second study finding significant fast priming with 32-ms primes but not primes of 29, 35, 38, or 41 ms (Lee, Rayner, \& Pollatsek, 1999). In a task combining both the boundary-based parafoveal preview manipulation and the fast-priming technique, Hohenstein, Laubrock, and Kliegl (2010) found significant parafoveal preview benefit only when parafoveal primes were visible for $125 \mathrm{~ms}$ before being replaced with the target word.

In sum, most of the available evidence on semantic priming has been acquired using isolated word recognition paradigms. Although semantic priming does occur during sentence reading, the effect is very sensitive to contextual factors when it is assessed by examining how gaze duration on a word is influenced by a semantically related word earlier in the sentence. Moreover, it remains uncertain whether semantic prime-target relations may affect eye movements differently than manual responses.

Although semantic priming effects are most often reported as differences in mean reaction times (RTs) across conditions, such analyses may not always capture the full range of relevant effects (Balota \& Yap, 2011). Although different types of distribution models may be suitable for capturing RTs, ex-Gaussian distributions have become increasingly popular within psycholinguistics, showing stable results both within and across experiments (Balota, Yap, Cortese, \& Watson, 2008; Staub \& Benatar, 2013), and have been successfully applied to data obtained using isolated word recognition as well as eye tracking during sentence reading (Staub \& Benatar, 2013; Staub, White, Drieghe, Hollway, \& Rayner, 2010). The ex-Gaussian distribution is a convolution of the Gauss- 
ian and exponential distributions, and can be described by three parameters (Ratcliff, 1979); mu $(\mu)$ and sigma $(\sigma)$, respectively, represent the mean and standard deviation of the Gaussian distribution and tau $(\tau)$ represents the mean and standard deviation of the exponential distribution, reflecting the degree of skew. Whereas mapping distributional parameters to cognitive processes requires additional theoretical and empirical support (Balota \& Yap, 2011; Matzke \& Wagenmakers, 2009), analyses of exGaussian parameter estimates allow for a qualitative comparison of the effect of different manipulations on the resulting RT distributions.

Balota et al. (2008) demonstrated that the semantic priming effect on lexical decisions is associated with a constant distributional shift, modulating $\mu$ but not $\sigma$ or $\tau$, a pattern that is consistent with interpretation of priming as a head-start or encoding-based effect. In contrast, priming for visually degraded targets was reflected in both $\mu$ and $\tau$, indicating that the effect of semantic relatedness across the distribution becomes increasingly more pronounced on slower trials (Balota et al., 2008; Yap, Balota, \& Tan, 2013). According to Balota et al. (2008), $\tau$-based effects of semantic relatedness reflect an adaptive response to target difficulty:

When the target is degraded, the system uses any available information available to better resolve the target, and hence, one finds the expected increase in effect size across Vincentiles. Consequently, the more difficult items, that is, those at the slowest Vincentiles, will be associated with more reliance on the prime information. (p. 519)

As such, shifts in $\tau$ are considered to reflect a retroactive priming process or process of postlexical checking specifically for the purpose of making a lexical decision (Balota et al., 2008; Neely, 1991; Yap et al., 2013).

However, if such task-based adaptation is a systematic principle of LD performance, it is surprising that its consequences are observed only when target difficulty is manipulated using visual degradation. Presumably, nondegraded targets also vary in difficulty because of word characteristics such as length and frequency, and this kind of inherent stimulus difficulty might be expected to prompt the flexible recruitment of prime information as well. Using clear targets, it has been found that participants can increase their reliance on prime information when task characteristics highlight the usefulness of the prime, for example, by having a high proportion of related trials (e.g., de Groot, 1984; Hutchison, 2007). Further, the interpretation of semantic priming as fully isolated in the encoding stage is inconsistent with the observed differences in the robustness of semantic priming across LDTs and sentence reading. If semantic preactivation effects on encoding are a general consequence of processing semantically related words, similarly robust effects of semantic relatedness should be observed in both types of tasks. The current experiments aim to distinguish between encoding-based and task-driven (or goal-driven) contributions to semantic priming by separating task-related effects from those related to the response mode. We replace the manual response mode typically used in an LDT with an eye-movement response through a sequence of three words. This ocular LDT combines the explicit control of task goals found in LDTs with the ocular response mode used in reading text.

The ocular LDTs used here are based on the triplet reading paradigm developed by Brysbaert (1995) for numbers, and used recently by Hoedemaker and Gordon (2014) to study encoding of numbers and words. The paradigm involves tracking participants' eye movements while they are presented with triplets of items (numbers or words) on which they must perform some task. A gaze-contingent display technique is used so that each letter string is visible only when it is fixated during first-pass reading; this technique prevents parafoveal preview or rereading of the first and middle letter strings, which increases the validity of gaze duration as a measure of lexical encoding. The gaze-contingent display of small sets of words provides a large amount of experimental control within a task that allows the eyes to move in a way that resembles regular reading (see Schroyens, Vitu, Brysbaert, \& D'Ydewalle, 1999, for a similar technique used to study parafoveal preview benefit). Semantic priming is studied by varying the relatedness of the middle word to the first word. The highly learned nature of the ocular response to word recognition is expected to result in faster performance than is observed for manual responses in comparable tasks (Grainger, O'Regan, Jacobs, \& Segui, 1989), and, in this way, should provide a more sensitive measure of the processes involved in word recognition during LDT. Ex-Gaussian distributions are fit to allow for a qualitative comparison of the effect of semantic relatedness on reading times across the RT distribution.

\section{Experiment 1}

In Experiment 1, participants were presented with triplets of words and were instructed to move their eyes from one letter string to the next if the letter string was a word; they were asked to press a button if the letter string was a nonword. Because participants provided LDs on all three words in each triplet, this paradigm resembles a continuous LDT (e.g., McNamara \& Altarriba, 1988; Shelton \& Martin, 1992). The experiment had three goals. The first goal was to assess the effect of response mode on LD performance, comparing the times in this ocular LDT to the manual LDT times in the ELP for the same words (Balota et al., 2007). We predicted that the ocular response mode would yield overall faster responses compared with manual RTs because forward saccades are a very highly practiced response to recognition of visual words. In contrast, we did not expect the ocular response mode to be associated with qualitative differences in lexical processing. For example, low-frequency words should be associated with sequential effects, such as frequency spillover, and with longer times in the ocular LDT, just as in the manual LDT. The second goal was to determine whether ocular LDs are influenced by semantic relatedness. Observation of a semantic priming effect for the middle word as a function of its relation to the initial word would demonstrate that ocular LDs, like manual LDs, are sensitive to semantic associations between stimulus words. The third goal was to examine the distribution in time of semantic-relatedness effects in the ocular task by fitting ex-Gaussian distributions to the ocular LD times. For manual LDs, semantic relatedness results in faster response times across the distribution, a pattern that is captured by shifts in the estimates for the ex-Gaussian parameters $\mu$ and possibly $\sigma$, but not $\tau$ (Balota et al., 2008; Yap et al., 2013). Observation of this same pattern for ocular LD times would extend evidence that semantic priming is the result of a head-start or preactivation process (Yap et al., 2013) to a case in which the baseline times for word recognition are predicted to be much shorter, meaning that even (very) short reading times are affected by the presence of a 
semantically related prime. Alternatively, ex-Gaussian distribution fits may reveal that the effect of semantic relatedness differs over the ocular RT distribution. Systematic differences in $\tau$, reflecting a more pronounced relatedness effect for slower RTs, would provide evidence that semantic priming is sensitive to task-related primeutility even when targets are clear and response times are relatively brief.

\section{Method}

Participants. A total of 33 undergraduate students from the University of North Carolina at Chapel Hill participated in this experiment for course credit. All participants were native speakers of English, with normal or corrected-to-normal vision, and were naïve to the research goals. Data from one participant were excluded from analyses because of very low task accuracy.

Stimuli. The experimental stimuli were presented as triplets of letter strings. Semantic relatedness was manipulated between words in the initial (prime) and middle (target) position of the triplets. These critical prime-target pairs were adapted from Lupker and Pexman (2010, Exp. 4), and consisted of 96 pairs of strongly semantically associated word pairs originally selected from Nelson, McEvoy, and Schreiber's (1998) association norms (mean forward association strength $=.62$; mean backward association strength $=.34$ ). The mean length of the target words was 4.57 letters, the mean orthographic neighborhood size was 7.96, and the mean log frequency per 51 million was 3.56 (Brysbaert \& New, 2009). Unrelated prime-target pairs were created by repairing each target with a different target's related prime. Thus, each list contained the same prime and target words, varying only the pairings of targets with related and unrelated primes. Two lists were created by dividing the prime-target pairs, so that all targets appeared once in each list, with half of the targets preceded by a related and half preceded by an unrelated prime.

To create triplets, a word or nonword was added in the final position, so that half of the related and half of the unrelated prime-target pairs were followed by a nonword. The words appearing in the final position were selected from Nelson et al. (1998) and had equivalent mean length and frequency to the prime and target words. In addition to the experimental trials, each list contained 48 trials $(20 \%)$ with an initial nonword, and 96 trials with an initial filler word and a nonword in the middle position, resulting in a .5 probability of a nonword appearing in the middle position in cases in which a word appeared in the initial position. The initial filler words preceding nonwords in the middle position were adopted from Lupker and Pexman (2010, Exp. 4). These primes were selected so that they, like the experimental primes, had a relatively strong associate in the Nelson et al. association norms. Altogether, this resulted in 240 trials (96 experimental and 144 filler trials) per list.

The 192 nonwords were selected from three different sources. The 48 standard nonwords from Lupker and Pexman's (2010) Experiment 4 made up $25 \%$ of all nonwords in the current experiment. The remaining nonwords were selected from the ELP (22\%; Balota et al., 2007) and the ARC nonword database (53\%; Rastle, Harrington, \& Coltheart, 2002). The nonwords were equivalent to the experimental primes and targets and to the filler words in length and orthographic neighborhood size.
Procedure. An SR EyeLink 1000 was used to record eye movements from the participants' dominant eye, as determined using the Miles or "hole-in-the-hand" test (Miles, 1930; Roth, Lora, \& Heilman, 2002). The stimuli appeared in a 20-point monospace font on a 20-in. ViewSonic G225f monitor at a viewing distance of $61 \mathrm{~cm}$, with a $120 \mathrm{~Hz}$ refresh rate and a $1024 \times 768$ display resolution rendering each letter about 11 pixels wide and $1^{\circ}$ of visual angle spanning approximately 2.5 characters. Each experimental session started with a 9-point calibration procedure; calibration was checked before each trial and the tracker was recalibrated when necessary. Each session lasted about $20 \mathrm{~min}$ and the experimenter monitored eye movements throughout the session.

Participants sat in a well-lit room, with a chin and forehead rest minimizing head movements. They were instructed to read the word triplets silently, and for each letter string decide whether it was a word or a nonword. They were instructed to move their eyes as quickly as possible to the next letter string in the triplet each time they decided a letter string was a word. If they decided the string was a nonword, they were to press a button on a hand-held console as quickly as possible. This button press ended the trial. If they reached the third and last string in the triplet and judged it to be a word, they were instructed to move their eyes to the bottom center of the screen. In the case of a correct decision, the words "Correct! Please press the button to proceed to the next trial" appeared in this position. If the participants made a forward saccade to the next letter string after deciding correctly that an initial or middle string was a word, the next word appeared without intervening feedback. However, if participants incorrectly pressed the button in response to a word presented in any position, or if they made an incorrect forward saccade from a nonword onto the next word position, the word "incorrect" was presented in red for $500 \mathrm{~ms}$ before the start of the next trial.

After initial calibration, each experimental session started with 10 warm-up trials, which did not contain any of the words used in the experimental list. These warm-up trials were excluded from all analyses. No primes, targets, filler primes or nonwords were repeated within a list. All experimental trials were presented in random order in a single block.

Each trial started with a fixation point on the left side of the screen. Once this point was fixated, the next screen appeared, containing three masks each consisting of three hash marks. The fixation point and the mask for the initial-, middle-, and final-word position were spaced approximately equally along the horizontal axis of the screen, with the center of the first word placed approximately 20 character spaces ( $8^{\circ}$ of visual angle) from the fixation point, and the centers of all three words placed approximately 23 character spaces $\left(9^{\circ}\right.$ of visual angle) from each other. Gazecontingent invisible boundaries were placed approximately 12 character spaces $\left(5^{\circ}\right.$ of visual angle) from the center of each word. The gaze contingencies were set up so that each word was unmasked only when the eyes entered its region on the screen from left to right during first-pass reading. Once the eyes left its region across the right boundary (thus simultaneously entering the next region and unmasking the next word), the mask reappeared and the word was no longer visible regardless of whether the participant made any regressive eye movements (See Figure 1). This method of stimulus presentation prevented both parafoveal preview and rereading of each word. 


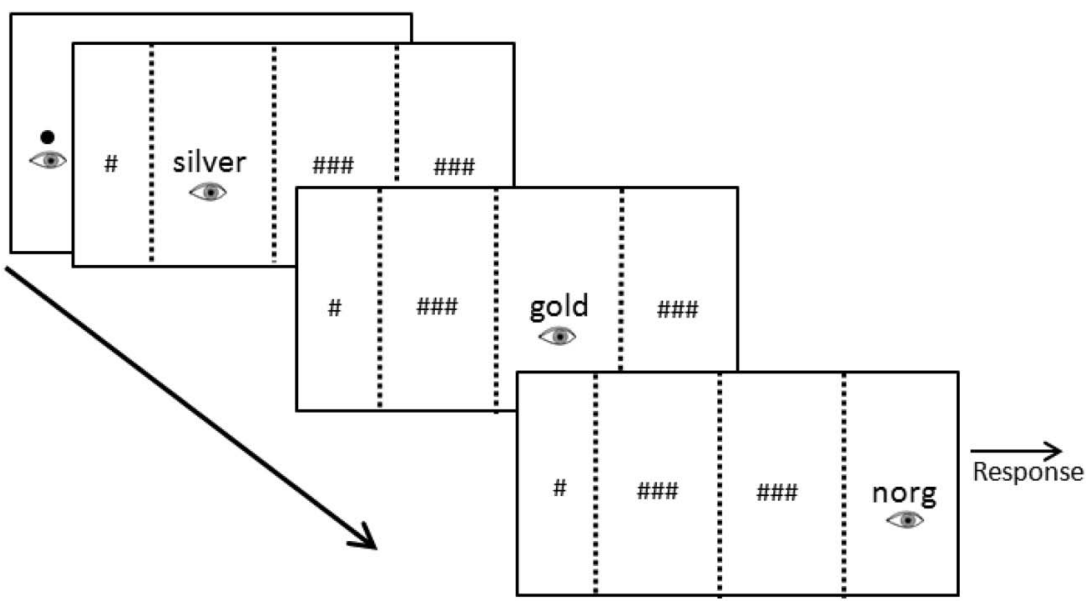

Figure 1. Presentation of stimuli in the ocular lexical decision task (LDT). Response time was measured as the gaze duration on each word. Nonwords are indicated via a speeded key press. On trials in which the final letter string was also a word, participants were instructed to look at the bottom of the screen. A gaze-contingent display technique was used, in which the words were masked except when the participant looked at them during their first reading pass from left to right. This eliminated preview and rereading of the first and middle word.

Analysis of eye movements. Fixations shorter than $80 \mathrm{~ms}$ and within $1^{\circ}$ of a longer, immediately subsequent fixation were merged with the longer fixation by an automatic procedure in the EyeLink software. Anomalously short display durations resulting from trigger misfiring were observed on $0.8 \%$ of trials, which were excluded from all further analyses. In some instances, display of a word was ended by a blink rather than a saccade. Elimination of affected data resulted in the further exclusion of $0.3 \%$ of word responses. Subsequently, fixations that were both shorter than 200 $\mathrm{ms}$ and located within 35 pixels (three character spaces or $1.3^{\circ}$ of visual angle) of an invisible boundary (1.2\% of all first-pass fixations on regions displaying a word) were removed from the analysis because it was considered very unlikely that any information about the word was gained from these fixations, which were both very short and quite far away from a visible word. In all but five instances, these short and remote fixations were part of a sequence of two or more fixations, suggesting that the removed fixations resulted from mistargeted saccades that were immediately followed by a corrective saccade. In cases in which the small delays in the display change caused a word to be unmasked slightly after the onset of the first fixation on a word, the timestamp of the fixation onset was adjusted to reflect the onset of the word display, excluding any time the participant was fixating the mask rather than the word; the adjustments averaged $11 \mathrm{~ms}$ (range $1 \mathrm{~ms}$ to $50 \mathrm{~ms}$ ). Finally, incorrect responses and responses that were more than three standard deviations above the mean for words in that position were removed from the analyses. Gaze durations that were less than $100 \mathrm{~ms}$ were also removed, based on the assumption that it is not possible to make a valid lexical decision in such a short amount of time. These criteria led to exclusion of $2 \%$ of the accurate word responses. The same exclusion criteria were used for the nonword key-press RTs, excluding $1.8 \%$ of correct nonword responses.

As participants were instructed to move their eyes to the next word in each triplet only if the current item was a word, gaze duration on each word was taken as a measure of both encoding and lexical decision time. Gaze duration is the sum of all first-pass fixation durations on a word and is widely used as a measure of lexical encoding in eye-tracking studies of reading (Inhoff, 1984; Morris, 1994; Rayner, 1998). Because of the gaze-contingent stimulus presentation, gaze duration in the current experiments was operationally equivalent to the time each word was visible on the screen, less the time spent in saccades. More importantly, as discussed later, the ocular LDT changes the customary interpretation of gaze duration as a pure measure of word encoding. We also consider three other widely used measures of first-pass reading. First-fixation duration (FFD) is the duration of the first fixation on a word. Single-fixation duration (SFD) is the fixation duration for those words that received only one first-pass fixation. Number of first-pass fixations is the number of first-pass fixations on a word. Although results for these measures are reported for completeness, gaze duration will be considered conceptually equivalent to response time in manual LDTs. Reaction time for nonwords was measured as the time from the onset of a word, triggered by the eyes entering the word's region, until the key press indicating the string was recognized as a nonword.

\section{Results}

General characteristics of ocular LDT performance. Mean accuracy in the task was $98 \%$ for words and $82 \%$ for nonwords. The ELP showed accuracies of $97 \%$ and $85 \%^{1}$ for manual LDTs with these words and nonwords, respectively. For both response modes, there appeared to be a bias toward word responses compared with nonword responses, with a greater bias seen for the ocular compared with manual LDT task. Across subjects, accuracy in the ocular task was consistently high for words (range of $91 \%$ to $100 \%$ ), whereas it was much more variable for nonwords (range of $58 \%$ to $95 \%$ ).

\footnotetext{
${ }^{1}$ Based on the 54 nonwords in the experiments for which ELP data are available.
} 
Table 1

Summary of Behavioral Measures in Experiment 1

\begin{tabular}{lccc}
\hline & Initial & Middle & Last \\
& $M(S D)$ & $M(S D)$ & $M(S D)$ \\
\hline Word GZD & & & \\
$\quad$ Related pairs & $431(87)$ & $361(47)$ & $461(51)$ \\
$\quad$ Unrelated pairs & $423(99)$ & $384(57)$ & $447(66)$ \\
$\quad$ Mean & $427(92)$ & $372(53)$ & $454(59)$ \\
Word FFD & & & \\
$\quad$ Related pairs & $285(50)$ & $295(22)$ & $347(44)$ \\
$\quad$ Unrelated pairs & $275(52)$ & $304(31)$ & $357(52)$ \\
$\quad$ Mean & $280(51)$ & $300(27)$ & $352(48)$ \\
Word SFD & & & \\
$\quad$ Related pairs & $382(91)$ & $339(38)$ & $447(97)$ \\
$\quad$ Unrelated pairs & $373(89)$ & $351(52)$ & $426(59)$ \\
$\quad$ Mean & $377(89)$ & $345(46)$ & $437(81)$ \\
Number of first-pass fixations on words & & & \\
$\quad$ Related pairs & $1.57(.25)$ & $1.35(.20)$ & $1.48(.24)$ \\
$\quad$ Unrelated pairs & $1.58(.24)$ & $1.38(.18)$ & $1.40(.28)$ \\
$\quad$ Mean & $1.58(.24)$ & $1.37(.19)$ & $1.44(.26)$ \\
Word accuracy & & & \\
$\quad$ Related pairs & $.98(.03)$ & $.99(.02)$ & $.97(.07)$ \\
$\quad$ Unrelated pairs & $.98(.03)$ & $.98(.05)$ & $.95(.09)$ \\
$\quad$ Mean & $.98(.03)$ & $.99(.04)$ & $.96(.07)$ \\
Nonword manual RT & $733(193)$ & $677(165)$ & $654(151)$ \\
Nonword accuracy & $.79(.16)$ & $.81(.09)$ & $.87(.09)$ \\
\hline
\end{tabular}

Note. The table contains mean gaze durations (GZD), first-fixations durations (FFD), single-fixation durations (SFD), number of first-pass fixations, nonword manual reaction times (RT), and accuracy rates for each position in the triplet.

Mean fixation times on critical trials and manual RTs for nonwords are shown in Table 1 . Mean gaze duration was $411 \mathrm{~ms}$ $(S D=48 \mathrm{~ms})$ for words in all three positions that were not preceded by a related word (i.e., middle words in the related-prime condition were excluded) compared with $605 \mathrm{~ms}(S D=51)$ for manual LDs to the same words in the ELP; this difference of 193 ms was highly significant, $t(335)=66.45 p<.001$, in a by-items analysis. Mean gaze durations on individual words were correlated with manual response times in the ELP, $r=.43, p<.001, R^{2}=$ $.18(n=336)$, a relationship that is likely related to the effect of word frequency on ease of recognition in both tasks. Gaze durations were negatively correlated with SUBTLEX log word frequency, $r=-.52, p<.001, R^{2}=.27(n=336)$, a relationship also found for the manual times from the ELP, $r=-.42, p<.001$, $R^{2}=.18(n=336)$. The correlation with frequency was marginally stronger for gaze durations than for the manual times from the ELP, $z=1.95, p=.05$ by the Fisher's $Z$ transformation (Meng, Rosenthal, \& Rubin, 1992), though the two studies had similar numbers of observations (approximately 32 observations per word in our task and 34 in the ELP).

Lexical spillover was measured by regressing each subject's gaze duration on the frequency of the preceding word after controlling for variables that could artificially inflate spillover effects. These control variables were trial number (there was a marginally significant reduction in reading times over the course of the experiment), frequency of the current word (word frequencies for words in related pairs were significantly correlated), and gaze duration on the previous word (there was a significant effect of response rhythm within a trial). Single-sample $t$ tests for the individual regression slopes showed a significant effect of the preceding word's lexical frequency on gaze duration, so that gaze durations were longer when the word in the previous position was higher frequency: ${ }^{2} B \mathrm{~s}, t(31)=3.18, p<.01$, and $\beta \mathrm{s}, t(31)=3.36$, $p<.01$ (middle position); $B \mathrm{~s}, t(31)=1.96, p=.06$, and $\beta \mathrm{s}$, $t(31)=2.07, p<.05$ (final position).

Semantic priming. Gaze durations on middle words were faster when the preceding word was semantically related than when it was unrelated, $t_{1}(31)=4.97, p<.001$, and $t_{2}(95)=4.95$, $p<.001$. The same effect was found for single-fixation duration, which comprised an average of $64 \%$ of gaze durations on middle words, $t_{1}(31)=2.28, p<.05$, and $t_{2}(95)=2.63 p<.05$, and first-fixation duration, $t_{1}(31)=2.29, p<.05$, and $t_{2}(95)=2.11$, $p<.05$. Middle words received slightly more first-pass fixations in the unrelated condition compared with the related condition, a difference that was significant by subjects, $t_{1}(31)=2.2, p<.05$, but not by items, $t_{2}(95)=1.59, p=.12$.

Accuracy for middle words was slightly higher in the related than in the unrelated condition, a difference that was not significant by subjects, $t_{1}(31)=-1.41, p=.168$, but was by items, $t_{2}(95)=-2.92, p<.01$; this trend should be interpreted with caution, as most participants made very few errors responding to words. Gaze durations for final words reversed the effect of association, showing longer times when the first and middle words were a related pair versus an unrelated pair. This effect was marginally significant by subjects, but did not reach significance in the by-items analysis, $t_{1}(31)=2.00, p=.05$, and $t_{2}(47)=1.61$, $p=.11$. The absence of a significant effect by items may be the

\footnotetext{
${ }^{2}$ The effect of association assessed in the same regression model remained significant, with shorter gaze durations on the middle word for related pairs: $B \mathrm{~s}, t(31)=-5.81, p<.001 ; \beta \mathrm{s}, t(31)=-5.94, p<.001$.
} 
result of there being fewer items in the third position, as half of the critical prime-target pairs were followed by a nonword instead of a word. However, assessment of individual regression slopes in the same model that was used to assess frequency spillover provided additional statistical support for this finding, showing significantly longer gaze durations on the final word when the initial and middle word were a related pair: $B \mathrm{~s}, t(31)=2.13, p<.05$, and $\beta \mathrm{s}, t(31)=$ $2.44, p<.05$. SFD (58\% of gaze durations on final words across subjects) and FFD did not show significant effects of relatedness on the final word, all $t \mathrm{~s}<1.5$, but there were marginally more fixations on final words after a related pair compared with after an unrelated pair, $t_{1}(31)=1.94, p=.06$, and $t_{2}(47)=1.87, p=.07$.

Ex-Gaussian distribution fit. Following Balota et al. (2008) and White and Staub (2012), we obtained ex-Gaussian parameter estimates for every participant's middle-word gaze durations separately for the related and unrelated prime conditions using the QMPE v2.18 program (Cousineau, Brown, \& Heathcote, 2004) for quantile maximum likelihood estimation. After exclusion of error trials and trimming outliers, as described earlier, the related and unrelated conditions had average observations per subject of 45.0 and 44.7, respectively. This exceeds the minimum of 40 observations per participant per condition that is recommended by Heathcote, Brown, and Mewhort (2002) to ensure reliable ex-Gaussian parameter estimates. Following Heathcote et al. (2002) and White and Staub (2012), the data were divided into the maximum number of quantile bins, so that each quantile bin effectively held a single data point. All fits converged within the 250-iteration limit, and the resulting parameter estimates were used as dependent variables in paired samples $t$ tests. Mean parameter estimates of $\mu, \sigma$, and $\tau$ are shown in Table 2. GZD did not show a significant effect of relatedness on $\mu, t(31)=1.28, p=.21$, or $\sigma, t(31)=1.51, p=$ .14 . In contrast, $\tau$ was significantly greater by an average of $17 \mathrm{~ms}$ in the unrelated condition compared with the related condition, $t(31)=3.21, p<.01$. FFD did not show a significant effect of relatedness on $\mu, t(31)=-.45, p=.66$, or $\sigma, t(31)=.01, p=$ 1.00 , but there was a numerical trend by which $\tau$ was greater ( 11 $\mathrm{ms}$ ) in the unrelated condition compared with the related condition, $t(31)=1.5, p=.14$. There were not enough single-fixation trials (i.e., there were fewer than the recommended 40 trials per condition for most subjects) to fit ex-Gaussian distributions for SFD.

To assess model fit, empirical Vincentiles were calculated by rank ordering each participant's RTs within a condition, and predicted Vincentile means were calculated based on 20,000 random samples generated from the mean across subjects of the best-fitting ex-Gaussian parameter sets for each condition (White \& Staub, 2012). Figure 2 shows a high degree of similarity in the predicted and observed Vincentile means, indicating that the model is very accurate. Inspection of Figure 2 also shows that the difference between reading times for unrelated and related words increases across the distribution, such that the priming effect is most pronounced for the slower Vincentiles. Excluding the rather noisy tenth Vincentile, this impression is confirmed by a significant linear interaction between relatedness and Vincentile, $F(1,31)=$ $16.2, p<.001$, which shows that the magnitude of the relatedness effect increased from faster to slower Vincentiles. The same procedure was followed for first-fixation duration, with the resulting plot shown in Figure 3. Again, inspection of the plot shows an accurate model fit, as well as an increasing difference between the related and unrelated condition across slower Vincentiles, and a significant linear interaction between the effect of relatedness on first-fixation duration and Vincentile across the first nine Vincentiles confirms this impression, $F(1,31)=7.5, p<.02$. Figure 4 shows observed Vincentile means for SFD by relatedness condition for trials with a single fixation. As discussed earlier, exGaussian parameters could not be calculated for single-fixation duration because of the smaller number of single-fixation trials. Nonetheless, inspection of the plot and a significant linear interaction between relatedness and Vincentile across the first nine Vincentiles show that magnitude of the priming effect increases across slower Vincentiles, $F(1,29)=8.1, p<.01 .^{3}$

Analysis of the priming effect in relation to the proportion of single- and multiple-fixation trials across Vincentiles shows that the $\tau$-based effect was not the result of a higher proportion of multiple fixation trials in slower Vincentiles. As shown in Figure 5 , there is an increase in multiple fixation trials as a function of Vincentile, but the difference across Vincentiles in the proportion of multiple-fixation trials as a function of semantic relatedness is not related to the magnitude of semantic priming across Vincentiles. Vincentile analyses of first-fixation and single-fixation duration (see above) provide further evidence that the magnitude of the priming effect increases across Vincentiles even when only first and single fixations are considered.

\section{Discussion}

Gaze durations in the ocular LDT were faster than the ELP's manual lexical decisions. Nonetheless, analysis of the condition means did not reveal qualitative differences in word recognition compared with manual LDT. Participants performed the task with word and nonword accuracies similar to those found in the ELP (Balota et al., 2007). Gaze durations showed a reliable semantic priming effect for target words, a facilitative effect of word frequency across word positions, and spillover effects of both frequency and relatedness that are consistent with adoption of a more stringent decision criterion following the processing of an easy word. However, ex-Gaussian distribution fits revealed important differences in how the effect of semantic relatedness was distributed for ocular compared with manual LDs.

For skilled readers, forward saccades are a highly practiced response to visual word recognition, which results in skilled reading having a very tight link between recognition decisions, response selection, and response execution during reading (Engbert et al., 2005; Gordon et al., 2013; Rayner \& Pollatsek, 1989; Reichle et al. 2003; Reilly \& Radach, 2006). This tight link is likely the cause of the much faster responses seen in the ocular LDT compared with the manual LDT. The dependence of ocular LDTs on word frequency is consistent with findings from both manual LDTs and eye tracking during sentence reading. The frequency spillover effect, in which ocular response times increased with greater frequency of the preceding word is consistent with the first-order sequential effect found by Perea and Carreiras (2003), in which manual lexical decisions to low-frequency words were slower when targets were preceded by unrelated high-

\footnotetext{
${ }^{3}$ This test has fewer degrees of freedom than the other Relatedness $x$ Vincentile ANOVAs because some participants had fewer than 10 singlefixation trials in one or both relatedness conditions, so that Vincentile means could not be computed.
} 
Table 2

Mean Ex-Gaussian Parameter Estimates for Distribution of Gaze Durations (GZD) and First Fixation Durations (FFD) on the Middle (Target) Word in Experiment 1

\begin{tabular}{|c|c|c|c|c|c|c|}
\hline & \multicolumn{3}{|c|}{ GZD } & \multicolumn{3}{|c|}{ FFD } \\
\hline & $M \stackrel{\mu}{(S D)}$ & $M \stackrel{\sigma}{(S D)}$ & $M \stackrel{\tau}{(S D)}$ & $M \stackrel{\mu}{(S D)}$ & $M \stackrel{\sigma}{(S D)}$ & $M \stackrel{\tau}{(S D)}$ \\
\hline Related & $280(51)$ & $30(19)$ & $81(26)$ & $232(35)$ & $58(23)$ & $62(34)$ \\
\hline Unrelated & $285(44)$ & $35(23)$ & 99 (27) & $230(35)$ & $58(25)$ & $73(41)$ \\
\hline Difference & 5 & 5 & 17 & -2 & 0 & 11 \\
\hline
\end{tabular}

frequency words compared with low-frequency words. Together with frequency-blocking effects-faster lexical decisions to highfrequency words in pure lists compared with high- and lowfrequency mixed lists (Glanzer \& Ehrenreich, 1979; Lupker, Brown, \& Colombo, 1997)—-these findings suggest that contextdependent criterion adjustments occur during LD tasks. In contrast, eye tracking during sentence reading tends to yield frequency spillover effects in the opposite direction, with faster first-pass reading times following high- than low-frequency words (Pollatsek, Juhasz, Reichle, Machacek, \& Rayner, 2008; Rayner \& Duffy, 1986). However, two points should be kept in mind when interpreting the frequency spillover effect observed here. First, the opposite patterns of spillover observed in reading depend largely on parafoveal preview of upcoming words, a process made impossible by the present use of a gaze-contingent display procedure. Second, the frequency-spillover effects in the current experiment were found in post hoc regression analyses rather than in a planned manipulation of the frequency transitions between word pairs. Nonetheless, semantic relatedness was associated with a similar criterion-based spillover effect, such that lexical decisions on the

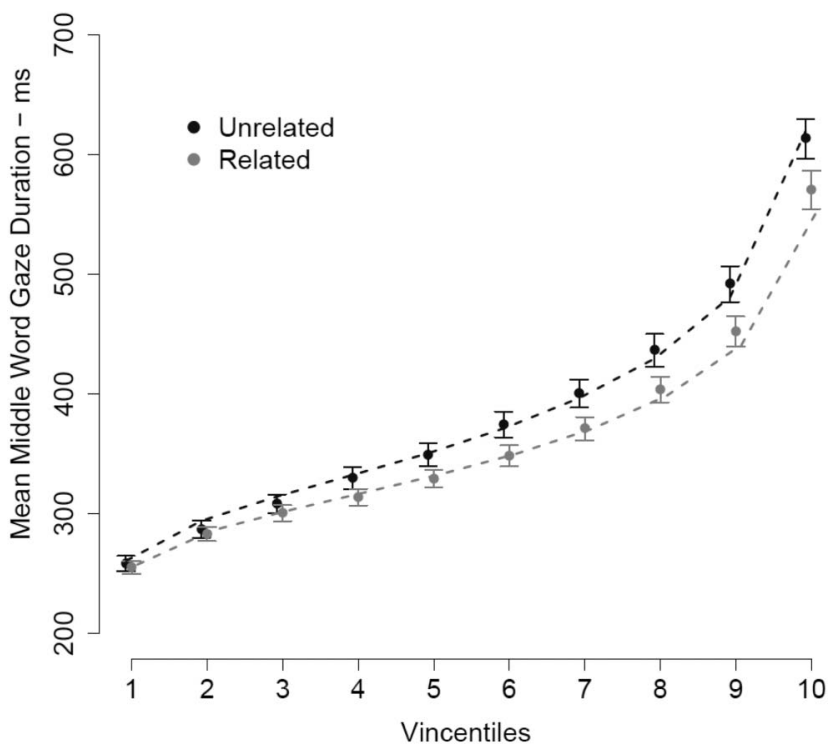

Figure 2. Vincentile plot for mean gaze durations on the middle word in Experiment 1, when the target was preceded by a related or an unrelated prime. Error bars show the standard error of the mean and dashed lines represent predicted Vincentile means based on mean ex-Gaussian parameters. final position were slower following a related pair in the initial and middle positions. Because the relatedness of the initial word pairs was experimentally manipulated, spillover of the semantic relatedness could be assessed without relying on regression techniques to remove the contributions of uncontrolled factors.

Taken together, the frequency and semantic spillover effects suggest that participants adopted a stricter "word" criterion after encountering words that were easier to recognize, either by virtue of high frequency or semantic relationship to the prime. Combined with the relatively high accuracy rates, these spillover effects provide evidence that words were fixated until sufficient evidence had been accumulated to make a correct LD response. If forward saccades in the ocular LDT had been executed before reaching the LD criterion, we would expect to see higher nonword error rates, and the need for residual processing of that word during fixation of the next word should have led to spillover effects in the opposite direction.

Fitting the ex-Gaussian distribution revealed several qualitative differences in the effect of semantic relatedness across manual and

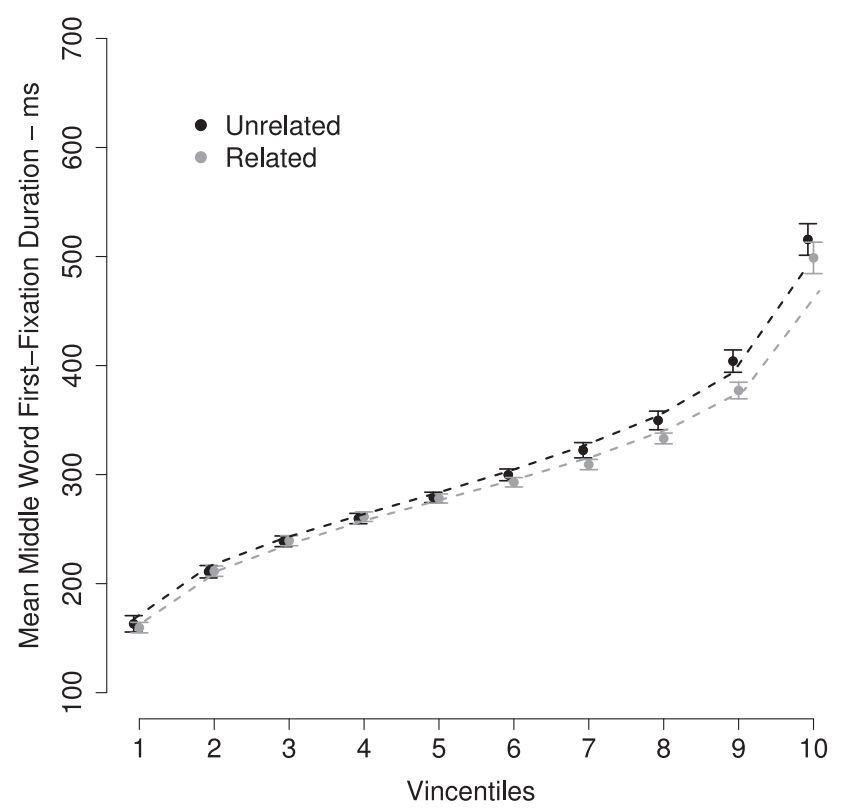

Figure 3. Vincentile plot for mean first-fixation durations on the middle word in Experiment 1, when the target was preceded by a related or an unrelated prime. Error bars show the standard error of the mean, and dashed lines represent predicted Vincentile means based on mean exGaussian parameters. 


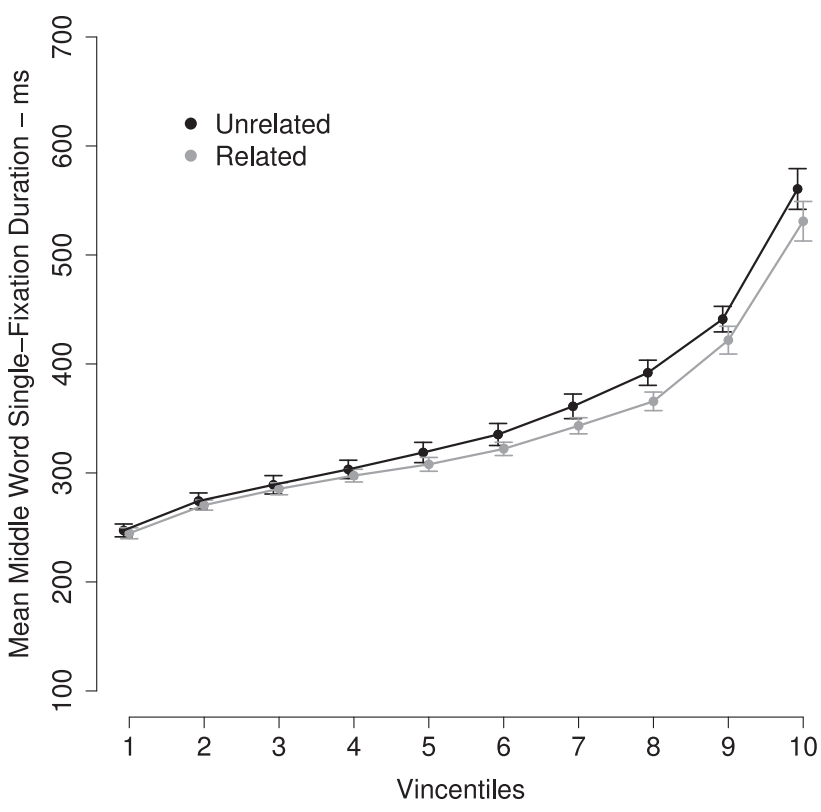

Figure 4. Vincentile plot for mean single-fixation durations on the middle word in Experiment 1, when the target was preceded by a related or an unrelated prime. Error bars show the standard error of the mean. No ex-Gaussian model fits are depicted, as there were not enough singlefixation trials to allow for a reliable ex-Gaussian distribution fit.

ocular LD distributions. Our analyses focus on gaze duration, as it is the eye-movement measure that is directly comparable to button-press time in a manual LDT. Both gaze duration in the ocular LDT and time in manual LDTs are determined by the response (saccade to the right or button press) that indicates that the letter string has been judged to be a word, whereas the task goals assign no such significance to first-fixation duration or number of fixations. Moreover, first-fixation durations, in cases in which a word receives two or more fixations, are less sensitive to lexical factors than are single-fixation durations (O'Regan \& Lévy-Schoen, 1987; Reingold, Reichle, Glaholt, \& Sheridan, 2012; Vitu \& O'Regan, 1995) and ex-Gaussian parameters could not be estimated for single-fixation duration because there were not enough trials with only one fixation. Whereas semantic priming in manual LD distributions takes the form of distributional shifts, reflected by changes in $\mu$ (Balota et al., 2008; Yap et al., 2013), ocular LD distributions failed to show such an effect and instead showed a reliable effect of relatedness on $\tau$. This distributional pattern was most pronounced for gaze duration, but firstfixation duration and single-fixation duration showed similar patterns and there was no evidence that the effect on $\tau$ depended on differences across relatedness conditions in the proportion of trials receiving multiple fixations. To our knowledge, only one previous study with visually intact targets has found evidence that semantic priming may be driven by changes in $\tau$; Yap, Tse, and Balota (2009) found an effect of semantic relatedness on estimates of $\tau$ (in addition to an effect on $\mu$ ) for low-frequency targets for readers with relatively low vocabulary knowledge when nonwords were pseudohomophones. As discussed in the introduction, Yap, Balota, and colleagues have interpreted effects on $\tau$ as indicating systematic sensitivity to the utility of the prime information, so that priming effects become more pronounced when target processing is slower and presumably more difficult (Balota et al., 2008; Yap et al., 2009, 2013). The more natural response mapping of the ocular LDT, associated with a very tight link between word recognition and execution of the forward saccade, may have allowed for the detection of this effect in the current experiment for readers with a range of vocabularies, visually intact stimuli, and a range of target frequencies.
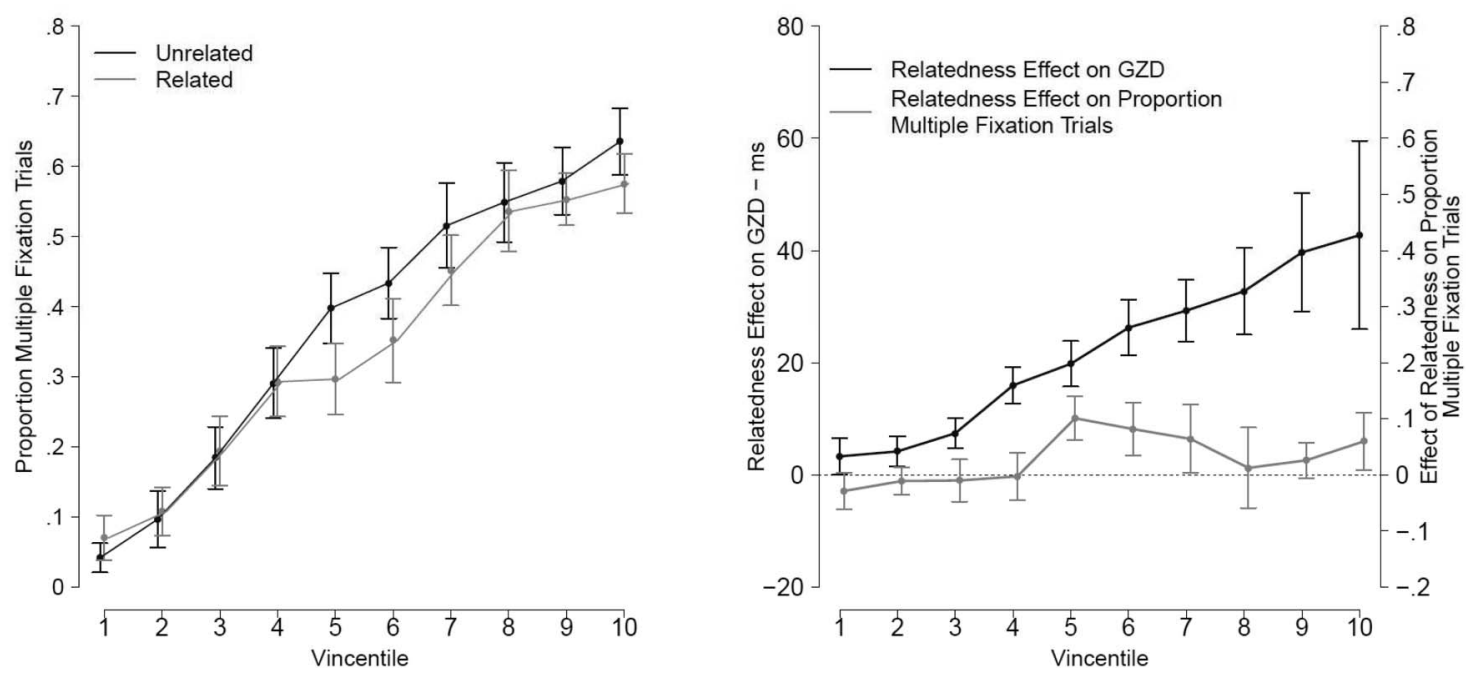

Figure 5. Left panel: Vincentile plot for mean proportion of multiple fixation trials on the middle word in Experiment 1, when the target was preceded by a related or an unrelated prime. Error bars show the standard error of the mean. Right panel: Dual-axes plot of the effect of semantic relatedness on gaze duration (GZD) as well as number of fixations across Vincentiles in Experiment 1. Error bars represent the standard error of the mean. 
Because semantic relatedness did not produce a consistent shift in response times across the distribution, Experiment 1 does not provide support for the interpretation (Balota et al., 2008; Yap et al., 2013) of semantic priming effects during LDT as a head-start or preactivation process. However, it would be unwarranted to reject this head-start interpretation based solely on this null result, especially in light of evidence for semantic priming in tasks that do not require an explicit lexical decision, such as sentence reading and speeded naming. For example, it is possible that noncognitive, oculomotor factors caused some reading times to be very short, leaving no time for any lexical analysis of the fixated word. However, if purely oculomotor factors were the main mechanism driving performance on the ocular LDT, then nonword error rates should be much higher than those observed in the manual LDT, which was not the case. The larger effect of relatedness in the slow end of the response distribution shows that priming was most pronounced for trials on which the LD took longer. Although there is no direct evidence that longer trials were associated with the demands of the LD task, the frequency- and relatedness-based spillover effects support the idea that the ocular LD responses reflect task-related behavior. The observation of flexible recruitment of prime information to support task performance on the ocular LDT supports the idea that semantic priming in this task is influenced by task-related processes.

\section{Experiment 2}

Forward saccades in the ocular LDT reflect the completion of a lexical decision process (as do key presses for manual LDTs), whereas forward saccades during sentence reading are not an indication that an explicit task goal has been met. Because there is no direct evidence about the criterion (or criteria) used for executing a forward saccade during sentence reading, interpretation of first-pass reading-time measures as an indication of word recognition is model dependent (Engbert et al., 2005; Gordon et al., 2013; Rayner \& Pollatsek, 1989; Reichle, Rayner, \& Pollatsek, 2003). Experiment 2 assesses whether semantic priming effects are observed for gaze durations in the ocular LDT under task conditions in which eye movements are not directly related to an explicit task goal. These task conditions adapt a nonword counting paradigm used in ERP studies of language processing (e.g., Bentin, Kutas, \& Hillyard, 1993). In the current experiment, subjects read triplets of letter strings on a gaze-contingent display that contained the same related prime-target pairs and nonwords used in Experiment 1. However, for this experiment, the lexical decision response was delayed until all three letter strings had been read, at which point subjects indicated how many nonwords had occurred in the triplet $(0,1,2$, or 3$)$ by making a speeded key press. ${ }^{4}$ The delayed response requirement in this cumulative $L D T$ separates encoding from response execution and possibly decision-based processes (see Hoedemaker \& Gordon, 2014).

Analysis of eye movements during the cumulative LDT focused on three points of interest. First, we assessed differences in word recognition times between the cumulative LDT, the ocular LDT (Experiment 1), and the manual LDT (ELP). We expected gaze duration on the initial and middle words in the cumulative LDT to be shorter than both the ocular and manual LDs, because processes involved in task-based decisions and response selection may be delayed until the eyes have moved past these regions of the triplet.
In addition, as gaze duration was no longer conceptually equivalent to response times in manual LDT, effects reflecting criterion adjustments (e.g., frequency spillover) would likely be absent or attenuated. Second, we assessed the role of semantic relatedness on gaze duration. The absence or attenuation of a semantic priming effect on gaze duration would support the idea that eye movements are less sensitive to semantic priming when they do not represent an explicit, task-related response. Third, ex-Gaussian distribution fits were used to assess whether delinking eye movements from response-to-task goals produces qualitative differences in the effect of semantic relatedness across the response-time distribution.

\section{Method}

Participants. Thirty-three participants from the University of North Carolina at Chapel Hill participated for course credit. All participants were native English speakers, with normal or corrected-to-normal vision, and were naïve about the research goals. Data from one participant were excluded because of low accuracy. None of the participants in Experiment 2 had participated in Experiment 1.

Stimuli. Experiment 2 contained the same 96 experimental stimulus triplets, as in Experiment 1. Again, the targets were distributed across two lists so that each target appeared in each list, with half the targets preceded by a related prime and half by an unrelated prime.

Because the experimental trials were always of the type: wordword-word or word-word-nonword, equal numbers of filler trials containing each of the other possible combinations of words and nonwords were added to each list, so that the conditional probability of a nonword appearing in any of the three word positions was always .5. This resulted in a total of 384 trials per list. The additional nonwords were selected from the ELP (Balota et al., 2007), and no words or nonwords were repeated within a list. All trials were presented in random order.

Procedure. The experimental setup and equipment were the same as in Experiment 1. Participants read the stimulus triplets while their eye movements were monitored. The triplets were presented on the same gaze-contingent display as in Experiment 1. Participants were instructed to read all three words silently. Once they had read the final word, participants indicated how many nonwords in total they had seen in that triplet by a speeded key press, choosing among buttons representing " 0 ," " 1, , " 2 ," or “ 3 " on a hand-held console. The final letter string remained visible until the response. Participants received accuracy feedback after every trial. The experimental session was preceded by eight warm-up trials containing letter strings that did not appear in the experimental triplets and were excluded from all analyses. Because of the large number of trials, the experiment was divided into two blocks of approximately equal length, with a short break between

\footnotetext{
${ }^{4}$ This paradigm in some ways resembles a LLDT, in which six 4-letter words are presented simultaneously and the participant's task is to decide whether any nonwords appear in the set (Lewis, Shvartsman, \& Singh, 2013). However, the LLDT differs from cumulative LDT because in LLDT, lists contain at most one nonword, and key-press responses may be indicated as soon as a nonword has been detected. In addition, LLDT thus far has not been applied to measure the effects of interword relationships on eye movements.
} 
blocks. The entire session lasted about $30 \mathrm{~min}$ and the experimenter monitored eye movements throughout the session.

Analysis of eye movements. Eye movements were analyzed as in Experiment 1. Anomalously short display durations caused by trigger misfiring led to exclusion of $1.1 \%$ of trials. In addition, $0.4 \%$ of words appearing in the first or middle position were excluded because the display change was triggered by a blink. Of the remaining fixations, $1.1 \%$ were both shorter than $200 \mathrm{~ms}$ and within 35 pixels from an invisible boundary. As in Experiment 1, such fixations were excluded from further analysis. In all but seven instances, these short and remote fixations were part of a sequence of two or more fixations, suggesting that the removed fixations resulted from mistargeted saccades that were immediately followed by a corrective saccade. For words requiring onset adjustment because of a delay in the display change, the average change in fixation onset time was $9 \mathrm{~ms}$ (range $1 \mathrm{~ms}$ to $180 \mathrm{~ms}$ ).

\section{Results}

Accuracy. Mean accuracy was $88 \%$ across all trials, and $92 \%$ across the critical trials containing a word in the initial and middle position. Incorrect trials were removed from all further analyses.

Word recognition times. Manual response times more than three standard deviations above the overall mean (2\%) were removed from the analysis. The same exclusion criteria for word gaze duration were used as in Experiment 1, resulting in the exclusion of $1.9 \%$ of all individual word gaze durations on first and middle words for correct trials. Mean fixation times on initial and middle words on critical (containing a related or unrelated word pair) trials are shown Table 3 .

Mean gaze duration across all trials was $363(S D=50)$ for words in the first and middle positions, excluding words in the middle positions that had been primed. Direct comparison of mean gaze durations for the 288 words that appeared in both Experiments 1 and 2 showed that gaze durations in Experiment 2 were, on average, $59 \mathrm{~ms}$ faster than in Experiment 1, a difference that was highly significant, $t(287)=20.33, p<.001$, in a by-items analysis. Mean gaze durations on individual words in Experiment 2 were correlated with gaze durations in Experiment $1, r=.29$, $p<.001, R^{2}=.08(n=288)$. As in Experiment 1 , this relationship likely results from the effect of word frequency on ease of word recognition. Gaze durations in Experiment 2 were negatively correlated with SUBTLEX $\log$ word frequency, $r=-.39, p<$ $.001, R^{2}=.15(n=384)$. However, a comparison of the correlations in Experiment 1 and 2 using the Fisher's $Z$ transformation (Meng et al., 1992) showed that the correlation with frequency was stronger in Experiment 1 compared with Experiment 2: $z=-4.47$, $p<.01$.

As in Experiment 1, lexical spillover was measured by regressing each subject's gaze duration on the frequency of the preceding word after controlling for trial number, frequency of the current word, and gaze duration on the previous word. Single-sample $t$ tests for the individual regression slopes showed a marginal effect of frequency spillover from the initial to the middle word, in the opposite direction than what was found in Experiment 1. Whereas gaze durations in Experiment 1 were longer when the word in the previous position was higher frequency, gaze durations on the middle word in Experiment 2 were shorter when the word in the initial position was higher frequency: ${ }^{5} B \mathrm{~s}, t(31)=-.99, p=.33$, and $\beta s, t(31)=-2.04, p=.05$. Because the final word always required a key-press response, lexical spillover on gaze durations could not be measured on this position.

Semantic priming. Reading times on the middle position showed a reliable effect of association, so that gaze durations were shorter when the target was preceded by an associated initial word: ${ }^{6} t_{1}(31)=4.20, p<.001$, and $t_{2}(95)=3.05, p<.01$. The same pattern was found for single-fixation duration (comprising $69 \%$ middle word gaze durations on critical trials across subjects), although the effect was marginally significant, $t_{1}(31)=1.75, p=$ .09 , and $t_{2}(95)=1.96, p=.05$. FFD did not show a significant effect of relatedness, $t_{1}(31)=1.26, p=.22$, and $t_{2}(95)=1.39$, $p=.17$, and there was no difference in mean number of fixations on the middle word across conditions, $t_{1}(31)=1.43, p=.16$, and $t_{2}(95)=.8, p=.40$.

Ex-Gaussian analysis. Following the same procedures used in Experiment 1, ex-Gaussian parameter estimates were obtained for each participant's gaze duration on the middle word for both related and unrelated trials. Mean parameter estimates in each condition are displayed in Table 4. After exclusion of error trials and trimming outlier values based on the procedure described previously, there was an average of 43.7 observations per subject in the related condition and 42.6 in the unrelated condition. All fits converged within the 250-iteration limit. Quantile-maximum probability estimation using the maximum number of quantiles revealed that for GZD prime-target relatedness did not have a significant effect on $\mu, t(31)=1.32, p=.19$, or on $\sigma$, $t(31)=-.47, p=.64$. Estimates for $\tau$ were an average of $9 \mathrm{~ms}$ higher for unrelated trials, resulting in a marginal effect of condition on $\tau, t(31)=1.83, p=.08$. Consistent with the means analysis of the semantic priming effect, ex-Gaussian fits for distributions of FFD did not show a significant effect of relatedness on mean estimates for any of the parameters (all $t \mathrm{~s}<1$ ). However, the effect on $\tau$ was numerically largest $(7 \mathrm{~ms})$. As in Experiment 1 , there were not enough trials (i.e., fewer than the recommended 40 trials per condition for most subjects) to fit ex-Gaussian distributions for SFD.

Observed and predicted Vincentiles are plotted in Figure 6 following the same procedure as in the previous experiment, and again showed a very good fit. Inspection of the priming effect across the Vincentiles indicates that the relatedness effect increased for the slower Vincentiles, an impression that is confirmed by significant linear interaction between relatedness and Vincentile after excluding the noisy tenth Vincentile, $F(1,31)=5.4, p<$ .05. As in Experiment 1, the priming effect is not the result of a difference in the number of multiple-fixation trials compared with

\footnotetext{
${ }^{5}$ The effect of association assessed in the same regression model remained significant, with shorter gaze durations on the middle word for related pairs: $B \mathrm{~s}, t(31)=-2.82, p<.01 ; \beta \mathrm{s}, t(31)=-3.83, p<.001$.

${ }^{6}$ There was a marginal effect of association on response times after reading the final word, so that button-press RTs were faster when the triplet contained a related pair of words in the initial and middle position compared with an unrelated pair, although this effect did not reach significance by items, $t_{1}(31)=1.86, p=.07$, and $t_{2}(95)=1.59, p=.12$, and assessment of individual regression slopes controlling for practice effects, frequency of the final word, and gaze duration on the preceding word did not confirm this result: $B \mathrm{~s}, t(31)=-1.00, p=.33 ; \beta \mathrm{s}, t(31)=-1.39$, $p=.17$.
} 
Table 3

Summary of Behavioral Measures in Experiment 2

\begin{tabular}{|c|c|c|c|}
\hline & $\begin{array}{c}\text { Initial } \\
M(S D)\end{array}$ & $\begin{array}{l}\text { Middle } \\
M(S D)\end{array}$ & $\begin{array}{c}\text { Last } \\
M(S D)\end{array}$ \\
\hline \multicolumn{4}{|l|}{ Word GZD } \\
\hline Related pairs & $331(65)$ & $325(47)$ & - \\
\hline Unrelated pairs & $334(62)$ & $339(48)$ & - \\
\hline Mean & $333(63)$ & $332(48)$ & - \\
\hline \multicolumn{4}{|l|}{ Word FFD } \\
\hline Related pairs & $239(34)$ & $271(30)$ & - \\
\hline Unrelated pairs & $243(35)$ & $277(34)$ & - \\
\hline Mean & $241(34)$ & $274(32)$ & - \\
\hline \multicolumn{4}{|l|}{ Word SFD } \\
\hline Related pairs & $294(60)$ & $305(43)$ & - \\
\hline Unrelated pairs & $299(61)$ & $312(42)$ & - \\
\hline Mean & $297(60)$ & $308(42)$ & - \\
\hline \multicolumn{4}{|c|}{ Number of first-pass fixations on words } \\
\hline Related pairs & $1.45(.20)$ & $1.31(.18)$ & - \\
\hline Unrelated pairs & $1.46(.21)$ & $1.33(.20)$ & - \\
\hline Mean & $1.45(.20)$ & $1.32(.19)$ & - \\
\hline \multicolumn{4}{|c|}{ Manual key-press RT } \\
\hline Related pairs & - & - & $1217(235)$ \\
\hline Unrelated pairs & - & - & 1252 (197) \\
\hline Mean & - & - & $1235(216)$ \\
\hline
\end{tabular}

single-fixation trials in the related and unrelated conditions, as shown in Figure 7. Vincentile analyses of first-fixation duration and single-fixation duration are not reported because these measures did not show significant main effects of relatedness on mean RTs.

\section{Discussion}

Gaze durations in Experiment 2 were reliably shorter than the ELP's manual LDs, as well as ocular LDs, in Experiment 1. This reduction in reading times likely reflects the separation of response selection from word recognition processes, so that gaze durations in Experiment 2 reflect a mixture of encoding and decision-related processes (Hoedemaker \& Gordon, 2014). Because of the lack of an explicit, task-based criterion for moving the eyes in the cumulative LDT, only indirect evidence can be used to separate the contributions to gaze durations of encoding-and decision-based processes. In Experiment 1, frequency and semantic spillover effects provided evidence for word-by-word criterion adjustments. In contrast, Experiment 2 showed a notably smaller frequency effect in the opposite direction, thus not providing any evidence for decision-related criterion adjustment. This lack of evidence supports the notion that gaze durations in Experiment 2 do not reflect decision-based processes to the same extent as gaze durations in Experiment 1. However, it must be kept in mind that Experiment 2 did not yield meaningful eye-movement data for the final world. As a result, it was not possible to measure spillover of semantic relatedness, and frequency spillover could only be measured on the middle word.

We observed reliable semantic priming on reading times as measured by gaze duration, although the effect was numerically smaller than in the ocular LDT, and marginal (SFD) or absent (FFD) in the means analysis of other first-pass eye-movement measures. Ex-Gaussian distribution fits for gaze duration revealed a concentration of semantic priming in estimates of $\tau$, so that semantic priming was more pronounced for slow compared with fast responses. Although the effect on $\tau$ did not quite reach significance at the .05 level, the significant relatedness by Vincentile interaction confirmed that the magnitude of the relatedness increased across Vincentiles. Semantic relatedness did not significantly affect $\mu$ or $\sigma$ estimates in the cumulative LDT.

Table 4

Mean Ex-Gaussian Parameter Estimates for Distribution of Gaze Durations (GZD) and FirstFixation Durations (FFD) on the Middle (Target) Word in Experiment 2

\begin{tabular}{|c|c|c|c|c|c|c|}
\hline & \multicolumn{3}{|c|}{ GZD } & \multicolumn{3}{|c|}{ FFD } \\
\hline & $M \stackrel{\mu}{(S D)}$ & $M \stackrel{\sigma}{(S D)}$ & $M \stackrel{\tau}{(S D)}$ & $M \stackrel{\mu}{(S D)}$ & $M \stackrel{\sigma}{(S D)}$ & $M \stackrel{\tau}{(S D)}$ \\
\hline Related & 248 (27) & 27 (12) & 78 (37) & 215 (34) & 47 (19) & $56(41)$ \\
\hline Unrelated & $252(26)$ & $26(15)$ & $87(40)$ & $213(35)$ & $50(20)$ & $63(41)$ \\
\hline Difference & 4 & -1 & 9 & -2 & 3 & 7 \\
\hline
\end{tabular}




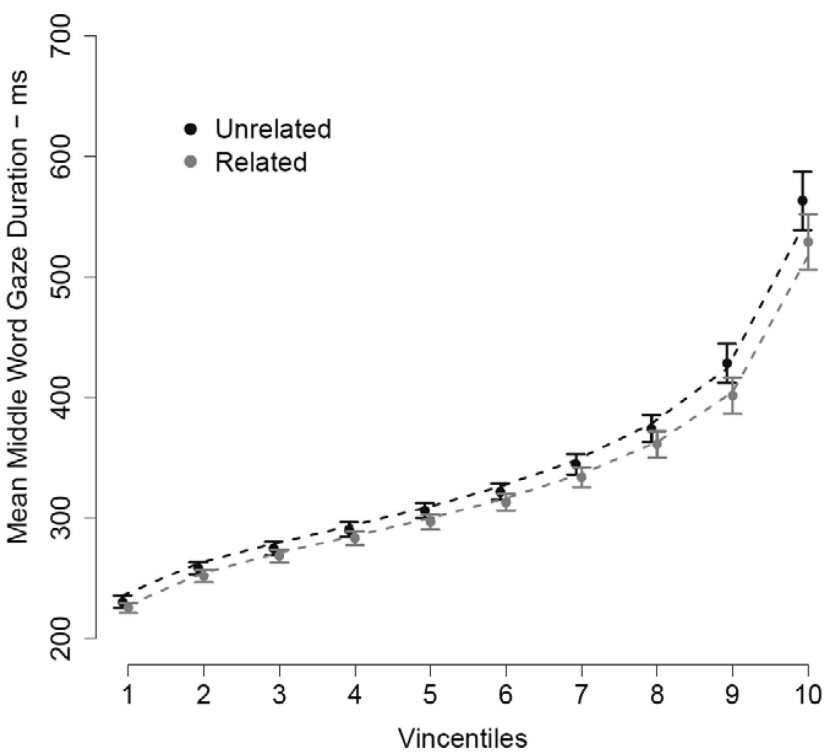

Figure 6. Vincentile plot for mean gaze durations on the middle word in Experiment 2, when the target was preceded by a related or an unrelated prime. Error bars show the standard error of the mean, and dashed lines represent predicted Vincentile means based on mean ex-Gaussian parameters.

In contrast to the immediate ocular LDT in Experiment 1, the cumulative nature of the task allowed participants to delay final decisions about lexicality until after the eyes had moved past the target word region, unless target resolution was especially difficult, resulting in the marginal $\tau$-based effect. This may explain why priming was weaker in the current experiment than in Experiment 1 , as the bulk of the LD-related processes likely took place after the eyes had left the target word regions, thus not contributing to the observed patterns of gaze durations.

\section{General Discussion}

This article presents the results of two lexical-decision experiments in which participants indicated their responses using forward saccades. Even though the ocular response times were much faster than those typically found for manual LDTs, semantic priming was observed in both the immediate (Experiment 1) and cumulative (Experiment 2) response conditions. Consistent with previous findings in manual LDT, response times in the immediate LDT suggested that participants adjusted their LD response criteria on a word-by-word basis, as indicated by spillover effects of both frequency and semantic relatedness. Ex-Gaussian distribution fits revealed an effect of semantic relatedness in estimates of $\tau$, but not $\mu$, for both tasks. The semantic priming effect was larger in the immediate than in the cumulative ocular LDT, but concentrated similarly in estimates of $\tau$. Figure 8 provides a direct comparison of Experiments 1 and 2 by plotting the priming effect as a function of mean target gaze duration in the unrelated condition. Although it is important to keep in mind that these data were obtained in two separate experiments with different participants, the plot suggests that differences in the magnitude of priming across the gaze distributions in Experiment 1 and 2 cannot be attributed solely to differences in baseline word recognition time. Even for overlapping portions of the ocular RT distributions, the observed priming effect in the immediate LDT is larger than in the cumulative LDT and increases more rapidly across the distribution. Taken together, these findings illustrate the importance of understanding how response mode and task demands affect word recognition processes across different types of tasks.

Although there is no necessary mapping between ex-Gaussian parameters and cognitive processes (Balota \& Yap, 2011; Matzke
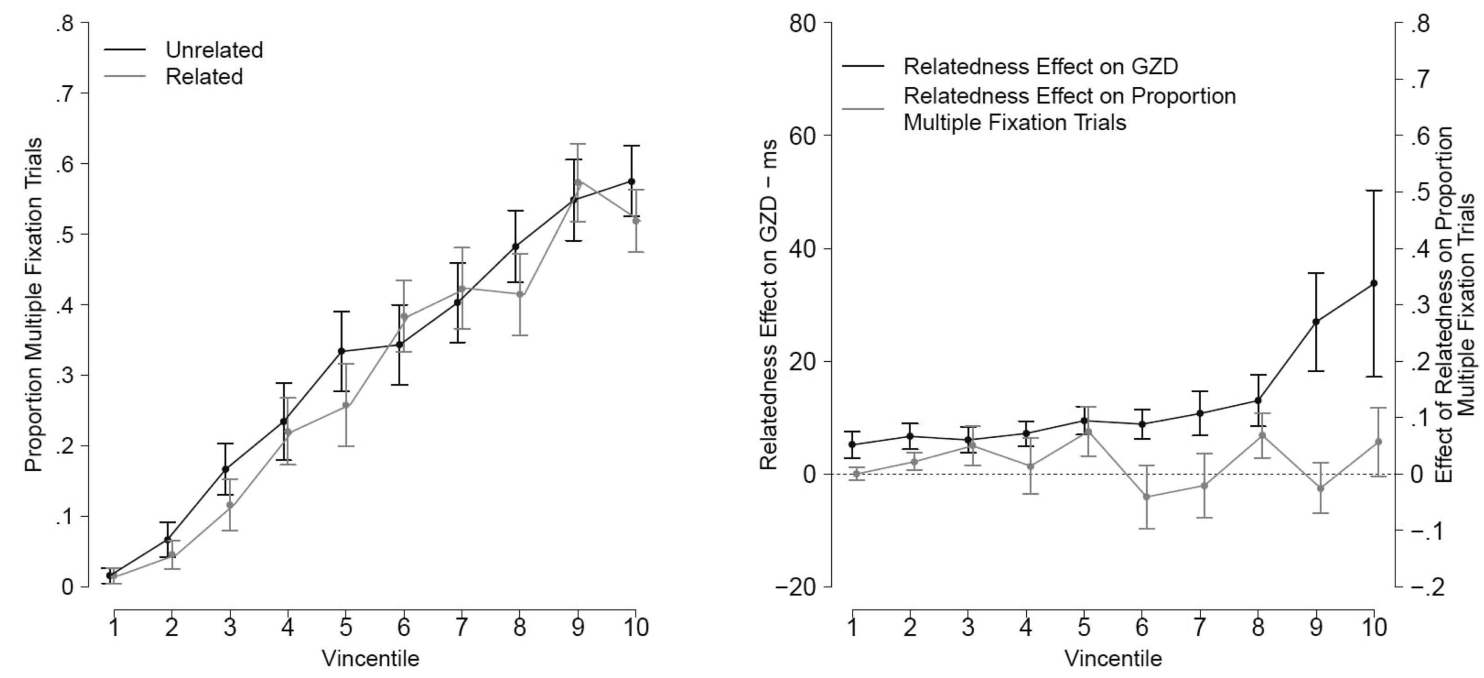

Figure 7. Left panel: Vincentile plot for mean proportion of multiple fixation trials on the middle word in Experiment 2, when the target was preceded by a related or an unrelated prime. Error bars show the standard error of the mean. Right panel: Dual-axes plot of the effect of semantic relatedness on gaze duration (GZD) as well as number of fixations across Vincentiles in Experiment 1. Error bars represent the standard error of the mean. 


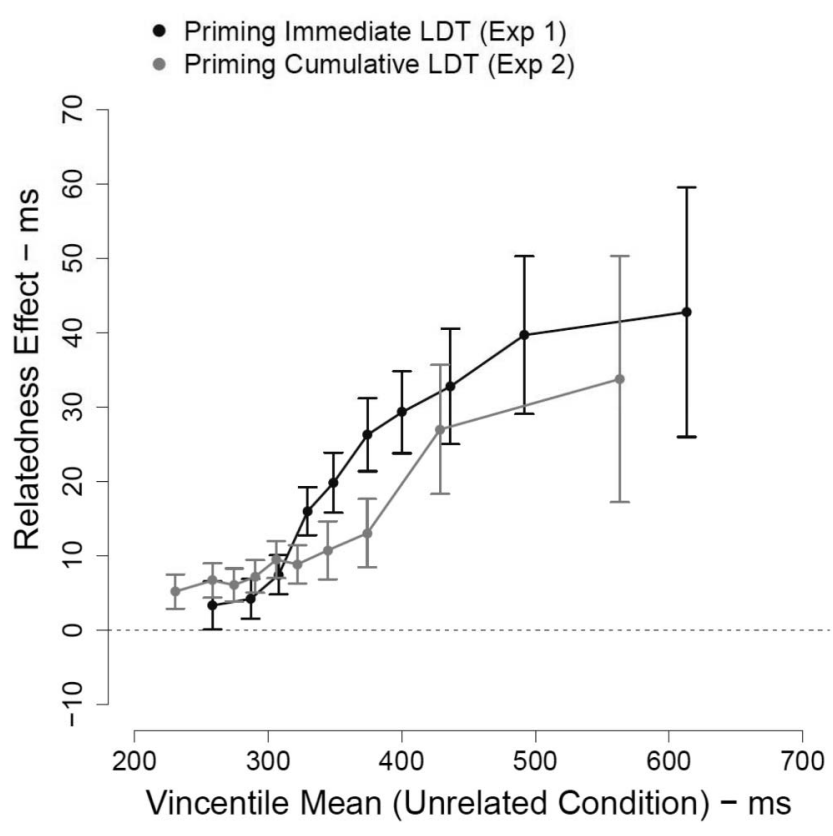

Figure 8. Priming effect (unrelated-related) across both experiments for gaze duration on the middle word, plotted as a function of the Vincentile mean in the unrelated-prime condition. Error bars represent the standard error of the mean. LDT $=$ lexical decision task.

\& Wagenmakers, 2009), previous studies of word recognition using ex-Gaussian fits have interpreted $\tau$-based effects as showing greater influence of the independent variable in cases in which processing is more effortful, while interpreting changes in $\mu$ as reflecting encoding-based mechanisms of word recognition. Yap, Balota, Cortese, and Watson (2006) found that the effect of nonword type on $\mathrm{LD}$ response latencies was marginal on $\mu$, but highly significant on $\tau$, consistent with the idea that the type of nonword used in an LDT more strongly affects decision processes than lexical encoding. Similarly, Yap, Balota, and colleagues have shown that manual LDs for degraded targets show effects of semantic priming on both $\mu$ and $\tau$, and have argued that this pattern reflects a systematic sensitivity to the utility of the prime information, which is more heavily recruited in cases in which target resolution is difficult and therefore slower (Balota et al., 2008; Yap et al., 2013).

Semantic priming in standard manual LDT has shown consistent effects on $\mu$, but not $\tau$, a pattern which has been interpreted as indicating that priming results primarily from a head-start or preactivation process. The observation here of a $\tau$-based priming effect points to an alternative priming mechanism - at least for ocular LDs. The concentration of the priming effect in the slower tail of the ocular LD distribution suggests that participants were able to flexibly recruit prime information when target resolution was difficult. Although there is no direct evidence that slower trials were associated with more difficult LDs, this interpretation is consistent with previous interpretations of $\tau$-based effects on measures of word recognition as reflecting increased effort (Balota et al., 2008; White \& Staub, 2012; Yap et al., 2013) or a disruption of processing (Staub \& Benatar, 2013). In addition, several empirical observations support the notion that the amount of required effort is particularly related to the difficulty of the lexicality decision. First, the immediate LDT in Experiment 1 provides evidence that the ocular response times reflect behavior directly related to the specific goals of the LDT. In particular, the semantic and frequency spillover effects show that criteria for the lexicaldecision judgment are, to some degree, influenced by the previous word. Second, the semantic priming effect was substantially weakened under conditions in which the response measure did not directly indicate the task decision for the trial. Finally, there is some evidence that simply increasing the duration of an LD response without manipulating $L D$ effort does not interact with stimulus-based effects. Lupker and Pexman (2010) showed that slowing LDs by making the LD more difficult by using more word-like nonwords resulted in a larger effect of target frequency, whereas an equal amount of slowing as a result of a manipulation unrelated to LD difficulty (the introduction of a task-switching component) did not interact with the effect of frequency. Although we have not investigated directly whether a similar dissociation exists for the effect of semantic relatedness, these results provide further support that trial duration on the ocular LD may be related to LD difficulty.

Some differences between conventional manual LDT and the ocular LDT should be considered. First, primes and targets in manual LDTs are typically presented sequentially in time at the same location on the display. In the ocular LDT tasks used here, they appeared at different locations, and semantic priming required integration of information across saccades. Observation of semantic priming in these ocular LDT tasks shows that such integration does take place, and no theoretical rationale is apparent for why such integration would cause priming across saccades to be decision-based or postlexical, while being encoding-based when the target replaces the prime in the same location. Moreover, if semantic priming were location-based then the fast-priming method (S. C. Sereno \& Rayner, 1992) would yield robust semantic priming because the prime and target word appear in the same physical location without intervening saccades. Second, manual LDTs typically present the primes for a fixed amount of time, whereas in our experiments, prime duration was determined by the participant. Although resulting prime presentation durations were longer than the 150- to 250-ms range used in many (but not all) manual LD studies, this procedure more closely resembles a continuous LDT (e.g., McNamara \& Altarriba, 1988; Shelton \& Martin, 1992), which is argued to be less prone to effects of task-based strategies (Hutchison, 2003; McNamara \& Altarriba, 1988).

The argument that semantic priming during LDT is affected by task-related processing may appear to conflict with findings of semantic priming when primes are masked (e.g., Perea \& Gotor, 1997; Perea \& Lupker, 2003; J. A. Sereno, 1991). However, although masked priming LDTs may reduce the possibility for conscious strategic processes to affect behavior, the task itself still requires a metalinguistic judgment of lexical status. Notwithstanding the brief, masked presentation of the prime, target processing times do not necessarily differ from those observed under nonmasked priming conditions, and, as such, are typically much longer than those observed in the ocular LDT. Consequently, it is likely that even under masked conditions prime information may be flexibly recruited in cases in which target resolution is especially difficult. For example, Balota et al. (2008) found a larger 
semantic priming effect with masked primes for degraded compared with visually intact targets, suggesting that participants increased their reliance on prime information when target resolution was difficult, even though they were not consciously aware of the primes. Moreover, masked priming with visually intact targets was reflected primarily by $\mu$, but masked priming with degraded targets was mediated by effects in both $\mu$ and $\tau$. These findings further support the notion that $\tau$-based priming effects reflect an adaptive recruitment of prime information in cases in which target resolution is difficult, even under masked priming conditions.

Differences in the response-mapping mechanism between ocular and manual LDs may provide an explanation for the discrepant patterns of priming on ex-Gaussian parameters. All models of eye movements during sentence reading recognize the importance of oculomotor and lexical factors, but differ in the extent to which lexical factors are considered to influence when and where the eyes move. Oculomotor models (e.g., McConkie, Kerr, Reddix, \& Zola, 1988; O’Regan, 1990; Yang \& McConkie, 2001) assume that saccades are generated at a relatively regular rate and minimally influenced by lexical processing. Such models are not directly applicable to the ocular LDT, as a process that initiated saccades independently of lexical processing would result in a large number of errors for nonwords. Although the error rate in the ocular LDT was higher for nonwords than for words, a similar pattern was observed in the ELP (Balota et al., 2007), suggesting that a bias to respond "word" can arise from processes that are not related to eye-movement control. Oculomotor factors may have led to short fixations in some cases, but cannot explain the pattern of results as a whole. Models that assign a larger role to cognitive processes, such as EZ Reader (Reichle, Rayner, \& Pollatsek, 2003) posit a tight integration between word recognition and eye-movement control. According to EZ Reader, saccade programming is initiated upon the completion of the first stage of lexical programming known as the "familiarity check" or "L1." Saccadic programming consists of two stages, an initial labile stage, in which the saccade can be cancelled and redirected, followed by a shorter, nonlabile stage, during which the saccade cannot be cancelled. Mean L1 processing is estimated at $122 \mathrm{~ms}$ (Pollatsek, Reichle, \& Rayner, 2006), and its duration is a function of word frequency and contextual predictability. Completion of the familiarity check signals that word recognition is imminent, but actual word identification (Stage L2) continues while the saccade to the next target is being programmed. The nature of the $\mathrm{L} 1$ familiarity check is not completely established, but recent findings on word skipping during reading (Choi \& Gordon, 2013, 2014) indicate that it is very sensitive to the lexical status of the letter string being processed. Thus, this L1 familiarity check may be sufficient to accurately perform the ocular LDT task for most words.

It should be kept in mind that EZ Reader was developed to account for eye-movement behavior during sentence reading as opposed to isolated word recognition tasks, and the account offered here represents one of several alternative hypotheses for the discrepant distributional patterns of priming between manual and ocular LDT. However, most cognitive models of eye movements during reading allot very little time between the completion of word recognition and the execution of a forward saccade to the next word. In other words, visual word recognition and eye movements are thought to be coordinated in such a way that there is very little waiting time during which the eyes are fixated on a target word that has already been sufficiently encoded. This tight connection between lexical processing and response programming may allow for subtle variations in word recognition time to result in observable interactions with the semantic priming effect. In contrast, the comparatively small amount of experience that participants have in making manual responses to visual words could be a source of more slack in the connection between basic word recognition and response execution, so that subtle differences in the duration of initial stages of word recognition are less likely to result in observable interactions between semantic priming and trial duration.

Importantly, the observation of task-related processing effects in the (ocular) LDT does not necessarily depend on consciously adopted strategies. A considerable body of research demonstrates that semantic priming occurs even when the LD paradigm is implemented in ways that prevent strategic processing (Fischler, 1977; McNamara, 2005; Neely, 1991; Shelton \& Martin, 1992) and in paradigms that do not require an overt binary decision (Forster, 1981; Neely, 1991; Perea \& Gotor, 1997). Moreover, the possibility for conscious strategic processes to affect performance on the LDT is substantially reduced in the ocular LDT because of its very short baseline response times. Instead, the LDT likely induces a particular task set causing greater sensitivity to information that may aid performance. Furthermore, these findings do not rule out that some portion of the semantic priming effect in LDT results from an encoding-based, preactivation process. This interpretation would certainly be more in line with evidence that semantic priming can occur during sentence reading (Camblin et al., 2007), as well as evidence that robust effects of priming in speeded pronunciation (Forster, 1981; Neely, 1991; Perea \& Gotor, 1997). Indeed, a recent diffusion model analysis by Gomez, Perea, and Ratcliff (2013) showed a small semantic priming effect on estimates of nondecision time $\left(\mathrm{T}_{\mathrm{err}}\right)$, which is interpreted to reflect encoding based processes. In sum, the results of the current study cannot be claimed to speak to the nature and origin of semantic priming effects across all elements of cognition. Rather, the ocular LDT provides a step in the exploration of how differences in response mode and task demands influence word recognition across contexts, and illustrates the importance of considering these factors when interpreting results from different types of tasks.

First-pass eye-movement measures during normal text reading are generally considered especially sensitive to processes of lexical encoding. This may render them less sensitive to goal-driven, effortful processing that has been found to affect $\tau$. For example, even though isolated word recognition studies have consistently found effects of visual quality on both $\mu$ and $\tau$ (e.g., Balota et al., 2008; Plourde \& Besner, 1997; Yap et al., 2013), eye tracking during reading has shown visual quality effects on $\mu$, but not $\tau$ (White \& Staub, 2012), for distributions of first-pass reading times. Similarly, effects on $\mu$, but not $\tau$, were found for word predictability (Staub, 2011; Sheridan \& Reingold, 2012). In contrast, word frequency has been observed to affect estimates of $\tau$ in eye-tracking measures as it does during manual LDT, possibly reflecting more effortful processing of low-frequency words (Reingold et al., 2012; Staub et al., 2010). The possibility for parafoveal preview during sentence reading may allow for some processing difficulty to be resolved before the eyes fixate a target word, rendering some effects more likely to appear as a head start 
reflected in $\mu$ (e.g., Reingold et al., 2012). According to White and Staub (2012), $\tau$-based effects on measures of eye movements during sentence reading may be elusive precisely because they reflect the controlled, attention-demanding processes required for successful performance on isolated word recognition tasks. Because of its highly practiced nature, eye-movement control during sentence reading does not rely on these processes as heavily, so $\tau$ is less prominent in distributions of gaze duration and less sensitive to experimental manipulation.

Alternatively, first-pass reading measures may be less likely to show $\tau$-based effects because the eyes are free to move about the text. During natural reading, more effortful processing of a particular word is expressed through not only greater first-pass reading times but also a greater number of regressive saccades, longer regression-path durations, and more second-pass reading, especially in cases in which the difficulty is semantic or related to discourse integration (Rayner, 1998). This may dilute the observation of semantic effects that are $\tau$-dependent on first-pass measures of sentence reading; such dilution does not occur during isolated word recognition tasks when all measurable effects are concentrated within a single measure of response time.

\section{Conclusion}

Effects of lexical and semantic variables on word recognition must be considered in conjunction with both task goals and response mode used to measure word recognition. Eye tracking during sentence reading provides data on a highly practiced behavior in a functionally important task. However, because of the lack of a direct link between eye movements and task goals, interpreting eye movements in relation to specific levels of word recognition is model dependent. Ocular isolated word recognition tasks, such as the ocular LDT, provide experimental control over task goals while allowing the eyes to move in a way that resembles regular reading. Nonetheless, as the goals of the LDT differ from those of word recognition during sentence reading, effects related to task-based processing cannot be expected to affect both measures in a similar manner.

\section{References}

Altarriba, J., Kambe, G., Pollatsek, A., \& Rayner, K. (2001). Semantic codes are not used in integrating information across eye fixations in reading: Evidence from fluent Spanish-English bilinguals. Perception \& Psychophysics, 63, 875-890. doi:10.3758/BF03194444

Anderson, J. R. (1983). A spreading activation theory of memory. Journal of Verbal Learning \& Verbal Behavior, 22, 261-295. doi:10.1016/ S0022-5371(83)90201-3

Balota, D. A., \& Chumbley, J. I. (1984). Are lexical decisions a good measure of lexical access? The role of word frequency in the neglected decision stage. Journal of Experimental Psychology: Human Perception and Performance, 10, 340-357. doi:10.1037/0096-1523.10.3.340

Balota, D. A., \& Lorch, R. F. (1986). Depth of automatic spreading activation: Mediated priming effects in pronunciation but not in lexical decision. Journal of Experimental Psychology: Learning, Memory, and Cognition, 12, 336-345. doi:10.1037/0278-7393.12.3.336

Balota, D. A., \& Yap, M. J. (2011). Moving beyond the mean in studies of mental chronometry the power of response time distributional analyses. Current Directions in Psychological Science, 20, 160-166. doi:10.1177/ 0963721411408885

Balota, D. A., Yap, M. J., Cortese, M. J., \& Watson, J. M. (2008). Beyond mean response latency: Response time distributional analyses of seman- tic priming. Journal of Memory and Language, 59, 495-523. doi: 10.1016/j.jml.2007.10.004

Balota, D. A., Yap, M. J., Hutchison, K. A., Cortese, M. J., Kessler, B., Loftis, B., . . . Treiman, R. (2007). The English Lexicon Project. Behavior Research Methods, 39, 445-459. doi:10.3758/BF03193014

Bentin, S., Kutas, M., \& Hillyard, S. A. (1993). Electrophysiological evidence for task effects on semantic priming in auditory word processing. Psychophysiology, 30, 161-169. doi:10.1111/j.1469-8986.1993 .tb01729.x

Boudewyn, M. A., Gordon, P. C., Long, D., Polse, L., \& Swaab, T. Y. (2012). Does discourse congruence influence spoken language comprehension before lexical association? Evidence from event-related potentials. Language and Cognitive Processes, 27, 698-733. doi:10.1080/ 01690965.2011.577980

Brysbaert, M. (1995). Arabic number reading: On the nature of the numerical scale and the origin of phonological recoding. Journal of Experimental Psychology: General, 124, 434-452. doi:10.1037/00963445.124.4.434

Brysbaert, M., Keuleers, E., Mandera, P., \& Stevens, M. (2013). Woordenkennis van Nederlanders en Vlamingen anno 2013: Resultaten van het Groot Nationaal Onderzoek Taal [Vocabulary knowledge of Dutch and Flemish in 2013: Results of the Groot Nationaal Onderzoek Taal]. Retrieved from http://crr.ugent.be/papers/Woordenkennis_van_ Nederlanders_en_Vlamingen_anno_2013.pdf

Brysbaert, M., \& New, B. (2009). Moving beyond Kucera \& Francis: A critical evaluation of current word frequency norms and the introduction of a new and improved word frequency measure for American English. Behavior Research Methods, 41, 977-990.

Camblin, C. C., Gordon, P. C., \& Swaab, T. Y. (2007). The interplay of discourse congruence and lexical association during sentence processing: Evidence from ERPs and eye tracking. Journal of Memory and Language, 56, 103-128. doi:10.1016/j.jml.2006.07.005

Carroll, P., \& Slowiaczek, M. L. (1986). Constraints on semantic priming in reading: A fixation time analysis. Memory \& Cognition, 14, 509-522. doi:10.3758/BF03202522

Choi, W., \& Gordon, P. C. (2013). Coordination of word recognition and oculomotor control during reading: The role of implicit lexical decisions. Journal of Experimental Psychology: Human Perception and Performance, 39, 1032-1046. doi:10.1037/a0030432

Choi, W., \& Gordon, P. C. (2014). Word skipping during sentence reading: Effects of lexicality on parafoveal processing. Attention, Perception, \& Psychophysics, 76, 201-213. doi:10.3758/s13414-013-0494-1

Collins, A. M., \& Loftus, E. F. (1975). A spreading-activation theory of semantic processing. Psychological Review, 82, 407-428. doi:10.1037/ 0033-295X.82.6.407

Cousineau, D., Brown, S., \& Heathcote, A. (2004). Fitting distributions using maximum likelihood: Methods and packages. Behavior Research Methods, Instruments \& Computers, 36, 742-756. doi:10.3758/ BF03206555

de Groot, A. M. (1984). Primed lexical decision: Combined effects of the proportion of related prime-target pairs and the stimulus-onset asynchrony of prime and target. The Quarterly Journal of Experimental Psychology A: Human Experimental Psychology, 36, 253-280. doi: 10.1080/14640748408402158

Engbert, R., Nuthmann, A., Richter, E. M., \& Kliegl, R. (2005). SWIFT: A dynamical model of saccade generation during reading. Psychological Review, 112, 777-813. doi:10.1037/0033-295X.112.4.777

Fischler, I. (1977). Associative facilitation without expectancy in a lexical decision task. Journal of Experimental Psychology: Human Perception and Performance, 3, 18-26. doi:10.1037/0096-1523.3.1.18

Forster, K. (1981). Priming and the effects of sentence and lexical contexts on naming time: Evidence for autonomous lexical processing. The Quarterly Journal of Experimental Psychology A: Human Experimental Psychology, 33, 465-495. doi:10.1080/14640748108400804 
Glanzer, M., \& Ehrenreich, S. (1979). Structure and search of the internal lexicon. Journal of Verbal Learning \& Verbal Behavior, 18, 381-398. doi:10.1016/S0022-5371(79)90210-X

Gomez, P., Perea, M., \& Ratcliff, R. (2013). A diffusion model account of masked versus unmasked priming: Are they qualitatively different? Journal of Experimental Psychology: Human Perception and Performance, 39, 1731-1740.

Gordon, P. C., Plummer, P., \& Choi, W. (2013). See before you jump: Full recognition of parafoveal words precedes skips during reading. Journal of Experimental Psychology: Learning, Memory, and Cognition, 39, 633-641. doi:10.1037/a0028881

Grainger, J., O’Regan, J. K., Jacobs, A. M., \& Segui, J. (1989). On the role of competing word units in visual word recognition: The neighborhood frequency effect. Perception \& Psychophysics, 45, 189-195. doi: 10.3758/BF03210696

Heathcote, A., Brown, S., \& Mewhort, D. (2002). Quantile maximum likelihood estimation of response time distributions. Psychonomic Bulletin \& Review, 9, 394-401. doi:10.3758/BF03196299

Hoedemaker, R. S., \& Gordon, P. C. (2014). Embodied language comprehension: Encoding-based and goal-driven processes. Journal of Experimental Psychology: General, 143, 914-929. doi:10.1037/a0032348

Hohenstein, S., Laubrock, J., \& Kliegl, R. (2010). Semantic preview benefit in eye movements during reading: A parafoveal fast-priming study. Journal of Experimental Psychology: Learning, Memory, and Cognition, 36, 1150-1170. doi:10.1037/a0020233

Hutchison, K. A. (2003). Is semantic priming due to association strength or featural overlap? A microanalytic review. Psychonomic Bulletin \& Review, 10, 785-813. doi:10.3758/BF03196544

Hutchison, K. A. (2007). Attentional control and the relatedness proportion effect in semantic priming. Journal of Experimental Psychology: Learning, Memory, and Cognition, 33, 645-662. doi:10.1037/0278-7393.33 .4 .645

Hutchison, K. A., Balota, D. A., Cortese, M. J., \& Watson, J. M. (2008). Predicting semantic priming at the item level. Quarterly Journal of Experimental Psychology (2006), 61, 1036-1066. doi:10.1080/ 17470210701438111

Inhoff, A. W. (1984). Two stages of word processing during eye fixations in the reading of prose. Journal of Verbal Learning \& Verbal Behavior, 23, 612-624. doi:10.1016/S0022-5371(84)90382-7

Keefe, D. E., \& Neely, J. H. (1990). Semantic priming in the pronunciation task: The role of prospective prime-generated expectancies. Memory \& Cognition, 18, 289-298. doi:10.3758/BF03213882

Lee, H. W., Rayner, K., \& Pollatsek, A. (1999). The time course of phonological, semantic, and orthographic coding in reading: Evidence from the fast-priming technique. Psychonomic Bulletin \& Review, 6, 624-634. doi:10.3758/BF03212971

Lewis, R. L., Shvartsman, M., \& Singh, S. (2013). The adaptive nature of eye movements in linguistic tasks: How payoff and architecture shape speed-accuracy trade-offs. Topics in Cognitive Science, 5, 581-610. doi:10.1111/tops.12032

Lupker, S. J., Brown, P., \& Colombo, L. (1997). Strategic control in a naming task: Changing routes or changing deadlines? Journal of Experimental Psychology: Learning, Memory, and Cognition, 23, 570-590. doi:10.1037/0278-7393.23.3.570

Lupker, S. J., \& Pexman, P. M. (2010). Making things difficult in lexical decision: The impact of pseudohomophones and transposed-letter nonwords on frequency and semantic priming effects. Journal of Experimental Psychology: Learning, Memory, and Cognition, 36, 1267-1289. doi: $10.1037 / \mathrm{a} 0020125$

Masson, M. E. (1995). A distributed memory model of semantic priming. Journal of Experimental Psychology: Learning, Memory, and Cognition, 21, 3-23. doi:10.1037/0278-7393.21.1.3

Matzke, D., \& Wagenmakers, E. (2009). Psychological interpretation of the ex-Gaussian and shifted Wald parameters: A diffusion model anal- ysis. Psychonomic Bulletin \& Review, 16, 798-817. doi:10.3758/PBR .16.5.798

McConkie, G. W., Kerr, P. W., Reddix, M. D., \& Zola, D. (1988). Eye movement control during reading: I. The location of initial eye fixations on words. Vision Research, 28, 1107-1118. doi:10.1016/0042 6989(88)90137-X

McNamara, T. P. (1992). Priming and constraints it places on theories of memory and retrieval. Psychological Review, 99, 650-662. doi: 10.1037/0033-295X.99.4.650

McNamara, T. P. (2005). Semantic priming: Perspectives from memory and word recognition. New York, NY: Psychology Press.

McNamara, T. P., \& Altarriba, J. (1988). Depth of spreading activation revisited: Semantic mediated priming occurs in lexical decisions. Journal of Memory and Language, 27, 545-559. doi:10.1016/0749596X(88)90025-3

McRae, K., de Sa, V. R., \& Seidenberg, M. S. (1997). On the nature and scope of featural representations of word meaning. Journal of Experimental Psychology: General, 126, 99-130. doi:10.1037/0096-3445.126 .2 .99

Meng, X., Rosenthal, R., \& Rubin, D. B. (1992). Comparing correlated correlation coefficients. Psychological Bulletin, 111, 172-175. doi: 10.1037/0033-2909.111.1.172

Meyer, D. E., \& Schvaneveldt, R. W. (1971). Facilitation in recognizing pairs of words: Evidence of a dependence between retrieval operations. Journal of Experimental Psychology, 90, 227-234. doi:10.1037/ h0031564

Miles, W. R. (1930). Ocular dominance in human adults. Journal of General Psychology, 3, 412-430. doi:10.1080/00221309.1930.9918218

Morris, R. K. (1994). Lexical and message-level sentence context effects on fixation times in reading. Journal of Experimental Psychology: Learning, Memory, and Cognition, 20, 92-103. doi:10.1037/0278-7393 .20.1.92

Morris, R. K., \& Folk, J. R. (1998). Focus as a contextual priming mechanism in reading. Memory \& Cognition, 26, 1313-1322. doi 10.3758/BF03201203

Neely, J. H. (1977). Semantic priming and retrieval from lexical memory: Roles of inhibitionless spreading activation and limited-capacity attention. Journal of Experimental Psychology: General, 106, 226-254. doi:10.1037/0096-3445.106.3.226

Neely, J. H. (1991). Semantic priming effects in visual word recognition: A selective review of current findings and theories. In D. Besner \& G. W. Humphreys (Eds.), Basic processes in reading: Visual word recognition (pp. 264-336). Hillsdale, NJ: Lawrence Erlbaum Associates.

Nelson, D. L., McEvoy, C. L., \& Schreiber, T. A. (1998). The University of South Florida word association, rhyme, and word fragment norms. Retrieved from http://web.usf.edu/FreeAssociation/

O'Regan, J. K. (1990). Eye movements and reading. In E. Kowler (Ed.), Eye movements and their role in visual and cognitive processes (pp. 395-453). New York, NY: Elsevier.

O’Regan, J. K., \& Lévy-Schoen, A. (1987). Eye movements strategy and tactics in word recognition and reading. In M. Coltheart (Ed.), Attention and performance XII: The psychology of reading (pp. 363-383). Hove, UK: Erlbaum.

Perea, M., \& Carreiras, M. (2003). Sequential effects in the lexical decision task: The role of the item frequency of the previous trial. The Quarterly Journal of Experimental Psychology A: Human Experimental Psychology, 56, 385-401. doi:10.1080/02724980244000387

Perea, M., \& Gotor, A. (1997). Associative and semantic priming effects occur at very short stimulus-onset asynchronies in lexical decision and naming. Cognition, 62, 223-240. doi:10.1016/S0010-0277(96)00782-2

Perea, M., \& Lupker, S. J. (2003). Does jugde activate COURT? Transposed-letter similarity effects in masked associative priming. Memory \& Cognition, 31, 829-841. doi:10.3758/BF03196438 
Plaut, D. C., \& Booth, J. R. (2000). Individual and developmental differences in semantic priming: Empirical and computational support for a single-mechanism account of lexical processing. Psychological Review, 107, 786-823. doi:10.1037/0033-295X.107.4.786

Plourde, C. E., \& Besner, D. (1997). On the locus of the word frequency effect in visual word recognition. Canadian Journal of Experimental Psychology, 51, 181-194.

Pollatsek, A., Juhasz, B. J., Reichle, E. D., Machacek, D., \& Rayner, K. (2008). Immediate and delayed effects of word frequency and word length on eye movements in reading: A reversed delayed effect of word length. Journal of Experimental Psychology: Human Perception and Performance, 34, 726-750. doi:10.1037/0096-1523.34.3.726

Pollatsek, A., Reichle, E. D., \& Rayner, K. (2006). Tests of the E-Z Reader model: Exploring the interface between cognition and eye-movement control. Cognitive Psychology, 52, 1-56.

Rastle, K., Harrington, J., \& Coltheart, M. (2002). 358,534 nonwords: The ARC nonword database. The Quarterly Journal of Experimental Psychology A: Human Experimental Psychology, 55, 1339-1362. doi: 10.1080/02724980244000099

Ratcliff, R. (1979). Group reaction time distributions and an analysis of distribution statistics. Psychological Bulletin, 86, 446-461.

Ratcliff, R., \& McKoon, G. (1988). A retrieval theory of priming in memory. Psychological Review, 95, 385-408. doi:10.1037/0033-295X .95.3.385

Rayner, K. (1975). The perceptual span and peripheral cues in reading. Cognitive Psychology, 7, 65-81. doi:10.1016/0010-0285(75)90005-5

Rayner, K. (1998). Eye movements in reading and information processing: 20 years of research. Psychological Bulletin, 124, 372-422. doi: 10.1037/0033-2909.124.3.372

Rayner, K., Balota, D. A., \& Pollatsek, A. (1986). Against parafoveal semantic preprocessing during eye fixations in reading. Canadian Journal of Psychology, 40, 473-483. doi:10.1037/h0080111

Rayner, K., \& Duffy, S. A. (1986). Lexical complexity and fixation times in reading: Effects of word frequency, verb complexity, and lexical ambiguity. Memory \& Cognition, 14, 191-201. doi:10.3758/ BF03197692

Rayner, K., \& Pollatsek, A. (1989). The psychology of reading. Englewood Cliffs, NJ: Prentice Hall.

Rayner, K., \& Schotter, E. R. (2014). Semantic preview benefit in reading English: The effect of initial letter capitalization. Journal of Experimental Psychology: Human Perception and Performance. Advance online publication.

Rayner, K., Schotter, E. R., \& Drieghe, D. (2014). Lack of semantic parafoveal preview benefit in reading revisited. Psychological Bulletin \& Review, 21, 1067-1072. doi:10.3758/s13423-014-0582-9

Reichle, E. D., Pollatsek, A., \& Rayner, K. (2006). E.-Z Reader: A cognitive control, serial-attention model of eye-movement behavior during reading. Cognitive Systems Research, 7, 4-22.

Reichle, E. D., Rayner, K., \& Pollatsek, A. (2003). The EZ reader model of eye-movement control in reading: Comparisons to other models. Behavioral and Brain Sciences, 26, 445-476. doi:10.1017/ S0140525X03000104

Reilly, R. G., \& Radach, R. (2006). Some empirical tests of an interactive activation model of eye movement control in reading. Cognitive Systems Research, 7, 34-55. doi:10.1016/j.cogsys.2005.07.006

Reingold, E. M., Reichle, E. D., Glaholt, M. G., \& Sheridan, H. (2012). Direct lexical control of eye movements in reading: Evidence from a survival analysis of fixation durations. Cognitive Psychology, 65, 177206. doi:10.1016/j.cogpsych.2012.03.001

Roth, H. L., Lora, A. N., \& Heilman, K. M. (2002). Effects of monocular viewing and eye dominance on spatial attention. Brain: A Journal of Neurology, 125, 2023-2035. doi:10.1093/brain/awf210
Rubenstein, H., Garfield, L., \& Millikan, J. A. (1970). Homographic entries in the internal lexicon. Journal of Verbal Learning \& Verbal Behavior, 9, 487-494. doi:10.1016/S0022-5371(70)80091-3

Rumelhart, D. E., \& McClelland, J. L. (Eds.). (1986). Parallel distributed processing: Explorations in the microstructure of cognition (Vol. 1). Cambridge, MA: MIT Press.

Schilling, H. H., Rayner, K., \& Chumbley, J. I. (1998). Comparing naming, lexical decision, and eye fixation times: Word frequency effects and individual differences. Memory \& Cognition, 26, 1270-1281. doi: 10.3758/BF03201199

Schotter, E. R. (2013). Synonyms provide semantic preview benefit in English. Journal of Memory and Language, 69, 619-633. doi:10.1016/ j.jml.2013.09.002

Schotter, E. R., Angele, B., \& Rayner, K. (2012). Parafoveal processing in reading. Attention, Perception, \& Psychophysics, 74, 5-35. doi:10.3758/ s13414-011-0219-2

Schroyens, W., Vitu, F., Brysbaert, M., \& D’Ydewalle, G. (1999). Eye movements control during reading: Foveal load and parafoveal processing. The Quarterly Journal of Experimental Psychology A: Human Experimental Psychology, 52, 1021-1046. doi:10.1080/713755859

Sereno, J. A. (1991). Graphemic, associative, and syntactic priming effects at a brief stimulus onset asynchrony in lexical decision and naming. Journal of Experimental Psychology: Learning, Memory, and Cognition, 17, 459-477. doi:10.1037/0278-7393.17.3.459

Sereno, S. C., \& Rayner, K. (1992). Fast priming during eye fixations in reading. Journal of Experimental Psychology: Human Perception and Performance, 18, 173-184. doi:10.1037/0096-1523.18.1.173

Shelton, J. R., \& Martin, R. C. (1992). How semantic is automatic semantic priming? Journal of Experimental Psychology: Learning, Memory, and Cognition, 18, 1191-1210. doi:10.1037/0278-7393.18.6.1191

Sheridan, H., \& Reingold, E. M. (2012). The time course of predictability effects in reading: Evidence from a survival analysis of fixation durations. Visual Cognition, 20, 733-745. doi:10.1080/13506285.2012 .693548

Staub, A. (2011). The effect of lexical predictability on distributions of eye fixation durations. Psychonomic Bulletin and Review, 18, 371-376.

Staub, A., \& Benatar, A. (2013). Individual differences in fixation duration distributions in reading. Psychonomic Bulletin \& Review, 20, 13041311. doi:10.3758/s13423-013-0444-x

Staub, A., White, S. J., Drieghe, D., Hollway, E. C., \& Rayner, K. (2010). Distributional effects of word frequency on eye fixation durations. Journal of Experimental Psychology: Human Perception and Performance, 36, 1280-1293. doi:10.1037/a0016896

Stone, G. O., \& Van Orden, G. C. (1993). Strategic control of processing in word recognition. Journal of Experimental Psychology: Human Perception and Performance, 19, 744-774. doi:10.1037/0096-1523.19.4 .744

Tabossi, P. (1982). Sentential context and the interpretation of unambiguous words. The Quarterly Journal of Experimental Psychology A: Human Experimental Psychology, 34, 79-90. doi:10.1080/ 14640748208400859

Traxler, M. J., Foss, D. J., Seely, R. E., Kaup, B., \& Morris, R. K. (2000). Priming in sentence processing: Intralexical spreading activation, schemas, and situation models. Journal of Psycholinguistic Research, 29, 581-595. doi:10.1023/A:1026416225168

Vitu, F., \& O'Regan, J. K. (1995). A challenge to current theories of eye movements in reading. In J. M. Findlay, R. Walker, \& R. W. Kentridge (Eds.), Eye movement research: Mechanisms, processes and applications (pp. 381-392). Amsterdam, Netherlands: North-Holland

White, S. J., \& Staub, A. (2012). The distribution of fixation durations during reading: Effects of stimulus quality. Journal of Experimental Psychology: Human Perception and Performance, 38, 603-617. doi: 10.1037/a0025338 
Yang, S. N., \& McConkie, G. W. (2001). Eye movements during reading: A theory of saccade initiation times. Vision Research, 41, 3567-3585. doi: $10.1016 / \mathrm{S} 0042-6989(01) 00025-6$

Yap, M. J., Balota, D. A., Cortese, M. J., \& Watson, J. M. (2006). Singleversus dual-process models of lexical decision performance: Insights from response time distributional analysis. Journal of Experimental Psychology: Human Perception and Performance, 32, 1324-1344. doi: 10.1037/0096-1523.32.6.1324

Yap, M. J., Balota, D. A., \& Tan, S. E. (2013). Additive and interactive effects in semantic priming: Isolating lexical and decision processes in the lexical decision task. Journal of Experimental Psychology: Learning, Memory, and Cognition, 39, 140-158. doi:10.1037/a0028520

Yap, M. J., Tse, C. S., \& Balota, D. A. (2009). Individual differences in the joint effects of semantic priming and word frequency revealed by RT distributional analyses: The role of lexical integrity. Journal of Memory and Language, 61, 303-325. doi:10.1016/j.jml.2009.07.001

Received December 15, 2013 Revision received July 7, 2014 Accepted July 9, 2014

\section{New Editors Appointed, 2016-2021}

The Publications and Communications Board of the American Psychological Association announces the appointment of 9 new editors for 6-year terms beginning in 2016. As of January 1, 2015, manuscripts should be directed as follows:

- History of Psychology (http://www.apa.org/pubs/journals/hop/), Nadine M. Weidman, PhD, Harvard University

- Journal of Family Psychology (http://www.apa.org/pubs/journals/fam/), Barbara H. Fiese, PhD, University of Illinois at Urbana-Champaign

- JPSP: Personality Processes and Individual Differences (http://www.apa.org/pubs/journals/ psp/), M. Lynne Cooper, PhD, University of Missouri-Columbia

- Psychological Assessment (http://www.apa.org/pubs/journals/pas/), Yossef S. Ben-Porath, PhD, Kent State University

- Psychological Review (http://www.apa.org/pubs/journals/rev/), Keith J. Holyoak, PhD, University of California, Los Angeles

- International Journal of Stress Management (http://www.apa.org/pubs/journals/str/), Oi Ling Siu, PhD, Lingnan University, Tuen Mun, Hong Kong

- Journal of Occupational Health Psychology (http://www.apa.org/pubs/journals/ocp/), Peter Y. Chen, PhD, Auburn University

- Personality Disorders (http://www.apa.org/pubs/journals/per/), Thomas A. Widiger, PhD, University of Kentucky

- Psychology of Men \& Masculinity (http://www.apa.org/pubs/journals/men/), William Ming Liu, PhD, University of Iowa

Electronic manuscript submission: As of January 1, 2015, manuscripts should be submitted electronically to the new editors via the journals Manuscript Submission Portal (see the website listed above with each journal title).

Current editors Wade E. Pickren, PhD, Nadine J. Kaslow, PhD, Laura A. King, PhD, Cecil R. Reynolds, PhD, John Anderson, PhD, Sharon Glazer, PhD, Carl W. Lejuez, PhD, and Ronald F. Levant, EdD, will receive and consider new manuscripts through December 31, 2014. 